NASA Technical Memorandum 102761

\title{
FINITE ELEMENT THERMO-VISCOPLASTIC ANALYSIS OF AEROSPACE STRUCTURES
}

\section{AJAY K. PANDEY}

PRAMOTE DECHAUMPHAI

EARL A. THORNTON

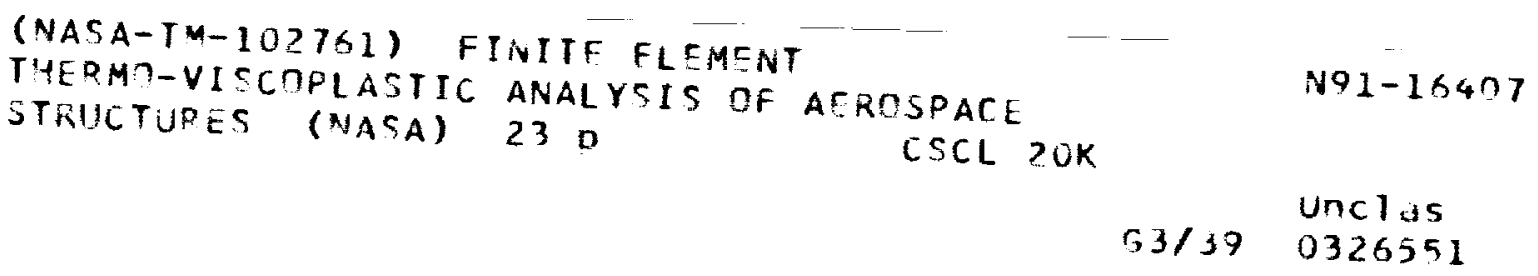

NOVEMBER 1990

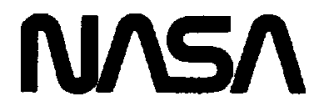

National Aeronautics and

Space Administration

Langley Research Center Hampton, Virginia 23665 



\title{
FINITE-ELEMENT THERMO-VISCOPLASTIC ANALYSIS OF AEROSPACE STRUCTURES
}

\author{
Ajay K. Pandey \\ Lockheed Engineering and Sciences Company \\ Hamplon, Virginia \\ Pramote Dechaumphai \\ NASA Langley Research Center \\ Iampton, Virginia \\ and \\ Earl A. Thomton \\ University of Virginia \\ Charlollesville, Virginia
}

\begin{abstract}
The time-dependent thermo-viscoplastic response of acrospace structures subjected to intense acrothermal loads is predicted using the finite-element method. The finite-element analysis uses the Bodner-Partom unified viscoplastic constitutive relations to determine rate-dependent nonlincar material behavior. The methodology is verified by comparison with experimental data and other numerical results for a uniaxially-loaded bar. The method is then used (1) to predict the structural response of a rectangular plate subjected to line heating along a centerline, and (2) 10 predict the thermal-structural response of a convectively-cooled engine cowl leading edge subjected to acrodynamic shockshock interference heating. Compared wo linear elastic analysis, the viscoplastic analysis results in lower peak stresses and regions of plastic defornations.
\end{abstract}

\section{INTRODUCTION}

As hypersonic velicles accelerate or decelerate, acrodynamic shock waves swecp across the vehicle and interact with local shocks and boundary layers. These shock interactions expose the vehicle surfaces to severe pressures and heating rates in local regions where the interactions occur. Leading edges present a particularly difficult design problem because of such intense, highly-localized loads. The thermal-structural response of hydrogen-cooled super "thermal" conducting leading edge subjected to intense acrodynamic heating was studied in [1]. A thermalstructural elasto/plastic analysis with experimental verification [2] of a cowl lip design demonstrated that plastic effects occur and may be significant.

Until recent years, the study of structural responsc at elevated temperatures duc to transient thermal and pressure loads was not possible because of an inability to model the viscoplastic material behavior. Traditionally, the thermal-structural analayis has been performed using elasto/plastic theories. These theories lack the capabilities to accurately model the load rate effect, cyclic material behavior, stress relaxation and other such phenomena. Over the last twenty years unified viscoplastic constitutive models have evolved to meet these nceds. These unified constitutive models provide a means for analytically representing a material's response from the elastic through the plastic range including strain-rate dependent plastic flow, creep, stress relaxation, and temperature effects. The first multi-dimensional formulation of viscoplastic constitutive model was due to Bodner and Partom [3]. Since then a number of constitulive models have appeared; many of these models and the related theories are summarized in review arlicles that appear in [4].

When unified constitutive models are implemented in finite element programs, it enables viscoplastic 
analysis of complex structures. Finite-element methods with unified constitutive models have been under development for the past 15 years. A thermo-viscoplastic finite-element computational approach for hypersonic structures was presented in [5]. Analysis of convectively-cooled hypersonic structures illustrated the effectiveness of the approach and provided insight into transient plastic structural behavior al elevated temperatures. Further application of the approach to high temperature structures and improvements in finite-element modeling techniques are required to: (1) assist in planning thermal-structural experiments to validate the computational approach, and (2) ald in understanding the high-lemperature belavior of difficule design problems such as leading edges of hypersonic vehicles.

The purpose of this paper is to present the thermo-viscoplastic analysis methodology, investigate its application to representative acrospace structures of current interest, and to investigate the need for such analysis. The Bodner-Partom unified constitutive relations and the therınal-structural equations are described first. Next, the finite-element formulation and the computational steps are presented for the thermo-viscoplastic analysis methodology. The methodlogy is evaluated by comparison of results for a uniaxially loaded bar with experimental duta and other finite-element results. The thermo-viscoplastic response of a plate subjected to line heating along the centerline is then obtained. The last application example presents the transient thermal-structural response of convectively-cooled engine cowl leading edge subjected $w$ intense aerodynamic heating and pressure.

\section{BODNER-PARTOM UNIFIED VISCOPLASTIC MODEL}

The structural analysis of acrospace structures at high temperature has traditionally been carried out by using either elastic or classical elasto/plastic analysis methodology [6]. The elastic analysis solution can't be relied upon once the material has yiclded because elastic constitutive relations are not valid. In classical time independent elasto/plastic theory, traditionally used for the post-yicld analysis, the structural behavior is predicted using a yicld condition (such as the von-Mises yield condition), a time independent flow rule (such as the Prandu-Reuss equation) and a hardening rule. Hardening rules are used to determine reverse yiclding under cyclic loading. A separate crecp law is required to predict creep behavior. This classical clasto/plastic theory can't predict the effect of varying strain rate [7] which is significant if the strain rate and temperature vary over a wide range.

Several unified viscoplastic models have been developed in recent years, which combine the time independent and time dependent response into a single inclastic component. These models utilize internal state variables as the repositories for the effect of past deformation history and do not rely on the existence of a conventional yield condition. A unified viscoplastic modcl $[3,8]$ is used in the present analysis because of its widespread use and its capability to closely simulate the time dependent material response under various kinds of loading [5,7].

The Bodner-Partom unified constitutive model represents plastic strain rate in terms of stresses and internal state variables. The internal state variable rates, in tum, ure given as functions of stresses, plastic work, and the current value of internal state variables. These equations, brichly described below, include certain physical concepts based on dislocation dynamics. Details of these equations are given in $[5,8]$ and are briefly described herein.

The strain-displacement relation wriuen in the rate form is,

$$
\dot{\varepsilon}_{i j}=\dot{\varepsilon}_{i j}^{p}+\dot{\varepsilon}_{i j}^{p}=\frac{1}{2}\left(\dot{u}_{i j}+\dot{u}_{j, i}\right)
$$

where $\varepsilon_{i j}$ denotes the total strain components and superscripts $E$ and $P$ denote elastic and plastic strain components, respectively. The displacement components are denoted by $u_{i}$ and the dot on top of the variable represents derivative with lime. The subscripts $\mathrm{i} j \mathrm{j}$ and $\mathrm{j}$, i denote differentiation with respect to the spatial coordinates. The plastic strain rate is described by the evolution equation (also known as flow rulc) and is given by [8],

$$
\hat{\varepsilon}_{i j}^{p}=\frac{S_{i j}}{\sqrt{J_{2}}} D_{0} \exp \left[-\frac{1}{2}\left(Z^{2} / 3 J_{2}\right)^{n}\right]
$$

where $D_{0}$ is the limiting shear strain rate, and $\mathbf{n}$ is the temperature dependent malerial parameter known as the strain rate sensitivity parameter. In the above equation, the deviatoric stress components, $S_{i j}$, are related to the stress components by, 


$$
S_{i j}=\sigma_{i j}-\frac{1}{3} \delta_{i j} \sigma_{k k}
$$

where $\delta_{\mathrm{ij}}$ is the Dirac delta function. The deviatoric stress invariant $\mathrm{J}_{2}$ is given in terms of deviatoric stress components by,

$$
J_{2}=\frac{1}{2} S_{i j} S_{i j}
$$

The variable $\mathrm{Z}$ appearing in Eq. (2) is interpreted as a load history dependent parameter (known as internal state variable) that represents hardness of the material with respect wo plastic flow. This internal state variable consists of isotropic $\left(Z^{l}\right)$ and directional $\left(Z^{l}\right)$ hardening components,

$$
\mathrm{Z}=\mathrm{Z}^{\mathbf{1}}+\mathrm{Z}^{\mathrm{D}}
$$

The rate of change of the internal state variable isotropic hardening component, $\dot{Z}^{1}$, is given by,

$$
\dot{Z}^{1}=m_{1}\left|Z_{1}-Z^{1}\right| \dot{W}_{p}-A_{1} Z_{1}\left[\frac{Z^{1}-Z_{2}}{Z_{1}}\right]^{r_{1}}
$$

where $m_{1}$ is the isotropic hardening rate; $Z_{1}$ and $Z_{2}$ are the maximun and minimum values of $Z^{I}$, respectively; constants $A_{1}$ and $r_{1}$ are temperature dependent matcrial constints, known as thermal recovery parameter and thermal recovery exponent, respectively; and the plastic work rate, $\dot{W}_{p}$, which is taken as measure of hardening, is given by,

$$
\dot{W}_{p}=\sigma_{i j} \hat{E}_{i j}^{p}
$$

The directional hardening component of the internal state variable, $Z^{\mathrm{D}}$, is given by,

$$
Z^{D}=\beta_{i j} a_{i j}
$$

where aij are the direction cosines of the current stress stake,

$$
\mathfrak{a}_{\mathrm{ij}}=\sigma_{\mathrm{ij}} /\left|\sigma_{\mathrm{k},} \sigma_{\mathrm{k} 1}\right|^{\frac{1}{2}}
$$

and the rate of change of the parameler $\beta_{\mathrm{ij}}$ has the same gencral form as that for isotropic hardening component (Eq. (4)) but has tensorial character.

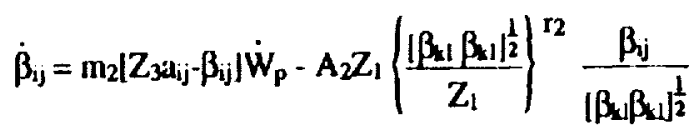

where $m_{2}$ is the directional hardening rate; $Z_{3}$ is the maximum value of $Z^{D} ;$ and $A_{2}$ and $D_{2}$ are the temperature dependent material constants, known as thermal recovery parameter and thernial recovery exponent, respectively.

In Eqs. (2-5), the parameters $D_{0}, Z_{1}, Z_{3}, r_{1}, r_{2}, m_{1}$, and $m_{2}$ are temperature-independent material constants; the parameters $n, Z_{2}, Z_{0}, A_{1}$, and $A_{2}$ are temperature-dependent material constants and all other parameters are problem variables. The material constants for different materials are given in [8-10] along with the detailed procedures for determining these constants. The particular values of these constants for the nickel-based superalloy (B1900+Hf), used in the present study, are given in the Appendix. 


\section{THERMAL-STRUCTURAL. FINITE-ELEMENT FORMULATION}

\section{Governing Equatiows}

The thermal response of the structure is govemed by the energy equation in the form,

$$
\rho c \frac{\partial T}{\partial t}+q_{i, i}=Q
$$

where $\rho$ is the density; $c$ is the specific heat; $T$ is the tcmperature; $Q$ is the internal heat generation rate; and $q_{i, i}$ is the spatial derivative of the heat flux $q_{i}$ in the $i_{\text {th }}$ direction. The conduction heat flux components, $q_{i}$, are related to the temperature gradients by Fouricr's law,

$$
q_{i}=-k_{i j} \frac{\partial T}{\partial x_{j}}
$$

where $k_{i j}$ is the temperature-dependent thermal conductivity tensor.

The structural response of the structure is goverend by the cquilibrium equations, written in rate form [5] as,

$$
\dot{\sigma}_{i j, j}+\dot{f}_{i}=0
$$

where $f_{j}$ are the body force components per unit volume. The stress rate conponents are related to the elastic strain rate components and the rate of change of temperature by the generalized Hooke's law,

$$
\sigma_{i j}=E_{i j k l}\left(\dot{\varepsilon}_{k i}^{k}-\alpha_{k l} \Delta \dot{T}\right)
$$

where $E_{j k}$ represents Hooke's tensor of elasticity parameters, and $\alpha_{k 1}$ arc components of a tensor of thermal expansion coefficients.

Finite-Element Equations and Solution Algorithm

The flux-based finite-clement approach [1] is used to derive the finite-clement equations for the thermal analysis. The flux-based finite-element approach is used because it reduces the computitional time and increases the solution accuracy $[1,11]$. The finitc-element cquations used to solve for rate of change of nodal temperatures, are in the form

$$
[M](\dot{T})=(R)_{1}+(R]_{2}
$$

where $[M]$ is the capacitance matrix. The two vectors on the right hand side are associated with the fluxes within the element and across the clement boundary, respectively. These vectors are delined by,

$$
\begin{aligned}
& {[R]_{1}=\int_{\Omega} \frac{\partial[N]}{\partial x_{i}}[N] d \Omega\left\{q_{i}\right]} \\
& {[R]_{2}=\int_{S}(N)[N] d s\left(q^{s}\right)}
\end{aligned}
$$

where $(N)$ are the interpolation functions; vector $(q)$ represents the nodal heat flux in the ith direction; ( $q^{s}$ ) vector represents the nodal heat flux on the boundary and includes specified heating, surface convection and surface radiation; symbols $\Omega$ and $s$ on the integral sign, respectively, denote domain and boundary integrals. An explicit time marching scheme (with lumped capacitance matrix) is used to oblain the transient temperalure response. Details of the matrices in Eq. (9) are given in [1]. 
The flux-based solution algorithm is also used to derive the finite-clement equations for the structural analysis [11]. The finitc-clement equations are given by,

$$
[\mathbf{K}](\dot{\mathbf{u}})=(\dot{\mathbf{R}})_{\mathbf{P}}+(\dot{\mathbf{R}})_{\mathrm{r}}+(\dot{\mathbf{R}})_{\boldsymbol{\sigma}}+[\dot{\mathbf{R}}]_{\mathbf{U}}
$$

where [K] is the element stiffness matrix. The load vectors on the right hand side of the above equation are associated with the rate of change of plastic strains, prescribed temperatures, surface tractions, and body forces, respectively. These load vecurs are defined by.

$$
\begin{aligned}
& {[\dot{R}]_{P}=\int_{\alpha}[B]^{T}[E]\left(\dot{\varepsilon}^{P}\right\} d \Omega} \\
& {[\dot{R}]_{T}=\int_{a}[B]^{T}[E][\alpha] \Delta \dot{T} d \Omega} \\
& \{\dot{\mathrm{R}}]_{\boldsymbol{\sigma}}=\int_{\mathbf{s}}[\mathrm{N}]^{\mathrm{T}}[\dot{\sigma}] d \mathrm{~s} \\
& {[\dot{R}]_{B}=\int_{\Omega}[N]^{T}(\dot{f}) d \Omega}
\end{aligned}
$$

where $[E]$ is the elasticity matrix; $[N]$ is the matrix of elcment interpolation funclions; $[B]$ is the strain-displacement matrix; $\Omega$ denotes the element domain; and $s$ denotes the boundary of the element where tractions are specified. Details of these matrices can be found in [12].

To predict the structural response, the solution algorithm procceds through the following steps:

1. Al time $\mathfrak{l}=0$, initialize stresses $\left(\sigma_{i j}\right)$ and internal state variable components $\left(Z^{\mathrm{I}}\right.$ and $\mathrm{Z}^{\mathrm{B}}$ ).

2. Compute plastic strain rates using Eq. (2).

3. Form finite-element matrices of $\mathrm{Eq}$. (10) and asscrnble them to obtain global malrix equations.

4. Solve global matrix equations $[K][\dot{u}]=(\dot{\mathrm{F}}]$ for displacement rales.

5. Compute strain rates from the displacement rales using Eq. (1).

6. Compute stress rates from the generalized Hooke's law using Eq. (8).

7. Compute the internal state variable rates using Eqs. (4-5).

8. Integrate stress rates and internal state variable rates to obtain the solutions of the stress components and internal state variables at time $t+\Delta t$.

9. If $t+\Delta t$. $<$ trual go to step 2, otherwise stop.

The above solution algorithm has been developed into a finite-element code, which includes eight-node three-dimensional hexahedral elements, four-node two-dimensional quadrilateral elements and three-node twodimensional triangular elements. The internal statc variable rates, plastic strain rates and other variable rate terms are integrated using Euler forward time integration scheme with a small time-step. Small time-step is required because the viscoplastic differential equations are very stiff in nalurc. The time-slep for viscoplastic analysis is chosen so that the computed solutions are smooth in time and don't diverge. The time-step for the viscoplastic analysis depends on the rate of applied thermo-mechanical loads. The clastic analysis solutions are computed at selected times, without any consideration of time-stcp.

\section{VERIFICATION OF METHODOLOGY AND APPLICATIONS}

The application of this viscoplastic analysis approach is presented for three different problems. The first application highlights simple material behavior by obtaining the thermo-viscoplastic response of a bar at uniform 
Lumperature subjected to uniaxial strain. The thermo-viscoplastic response of a rectangular plate under intense line heating is presented as the second application. A convectivcly-cooled leading edge structure is then analyzed for transient thermal and viscoplastic response. A high temperature nickel-based superalloy $(\mathrm{B} 1900+\mathrm{HI})$ is used as the structural material in all the example problems. The malerial properties are listed in the Appendix.

\section{Uniaxial Loading of a Bar}

The viscoplastic behavior of a nickel superalloy bar subjected to different struin rates and temperatures were reported for the NASA Lewis HOST (HOt Section Technology) program [9,10]. The authors compared the bar's experimental viscoplastic response with a finite element solution to verify the capability of the Bodner-Partom constitutive model in predicting the effects of strain rate and temperatures on the stress-strain response of the material. In the present example, the finite-element algorithm, described in previous sections, is used to predict response of the bar and results are compared with numerical and experimental results from $[9,10]$. The numerical results in $[9,10]$ were obtained using the MARC finite-element code, which was modified to include a subroutine for Bodner-Partom unified constitutive model. The finite-element model of the bar consists of one three-dimensional eight-node hexahedral element. The bar is fixed at one end, while the other end is subjected to loading.

In the first experiment, the end of the bar is subjected to tensile strain at a rate of $100 \mu \mathrm{in}$./in.-s at three different temperatures of $2060^{\circ} \mathrm{R}, 2260^{\circ} \mathrm{R}$ and $2460^{\circ} \mathrm{R}$. Computed stress-strain curves compare well with the strain controlled experimental data and finite element results from [9] as shown in Fig. 1. The stress-strain curve is lincar for small values of strain, then yiclding starts, and a saturation stress level is reached, above which strain increases without any further increase in stress. The saturation stress refers to the stress value, which corresponds to the material plastic flow. As the temperature of the bar is increased (sce Fig. 1), the material softens and a lower value of saturation stress is obtained. The elastic modulus is reduced as temperature increases, as shown in Fig. 1.

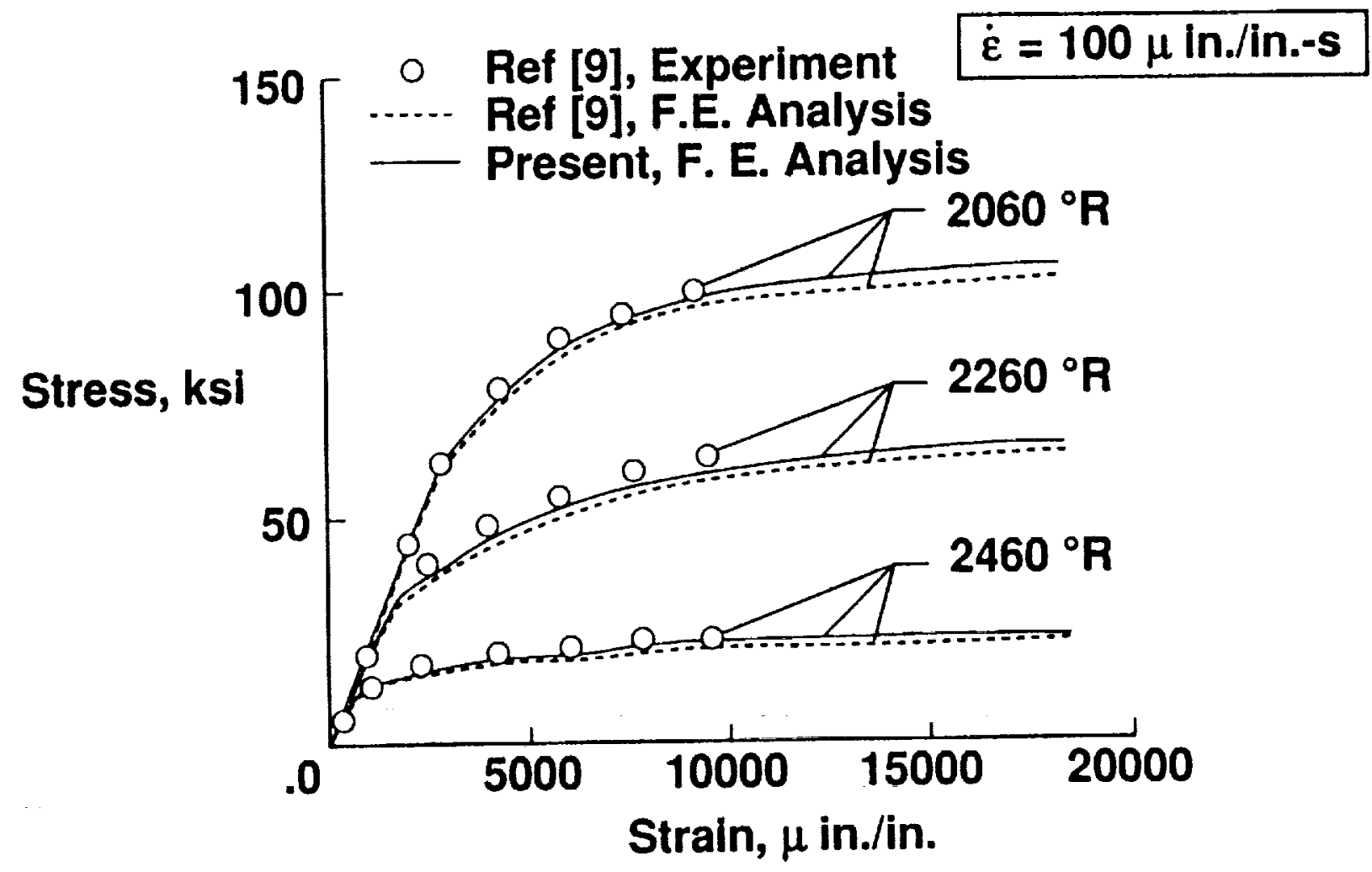

Fig. 1 Effect of temperarture on the stress-strain curves of a nickel-based superalloy (B1900+Hf) bar at a uniaxial strain rale of $100 \mu \mathrm{in}$ /in.-s. 
The effect of different applied strain rates on the bar is presented in the second experiment. In this second experiment, the bar is kept at a constant temperature of $2060^{\circ} \mathrm{R}$. The stress-strain curves, computed using the present methodology, compare well with experimental data and another numerical solution [9] for three different strain rates as shown in Fig. 2. The material behavior is unique and linear for small strain. At higher strain levels, the material response is not unique at different strain rates because of the viscoplastic effect. The material becomes harder when it is pulled at a higher strain rate (e.g. at $4000 \mu$ in./in.-s), resulting in a higher value of saturation stress.

Creep phenomena is demostrated by applying a constant load to an isothermal bar. The strain increases with time without any increase in applied load, which is the basic characteristic of creep loading. Strain history compares well with the available experimental results and numerical solution [10] as shown in Fig. 3. The figure shows that an isothermal bar at $2060^{\circ} \mathrm{R}$ and at a constant applied stress of $74 \mathrm{ksi}$ results in a larger creep strain rate than the bar at $2460^{\circ} \mathrm{R}$ and at a constant applied stress of $12 \mathrm{ksi}$. The effect of cyclic load at two different temperatures, $2060^{\circ} \mathrm{R}$ and $2260^{\circ} \mathrm{R}$, is shown in Fig. 4. The bar is subjected to a maximum of $\pm 1.5 \%$ strain at a rate of $\pm 100 \mu$ in./in.-s. The virgin isothermal bar is subjected to the cyclic strain loading and two stress-strain curves are obtained corresponding to two different temperatures. At higher temperature, the saturation stress level is lower in both tension and compression. Significant plastic strain is observed at zero stress level with relatively more plastic strain for the bar at higher temperature.

The above example problems highlight some of the material responses, which are predicted using the Bodner-Partom viscoplastic model applied to a uniaxially-loaded bar. These examples also validate the present methodology and analysis code.

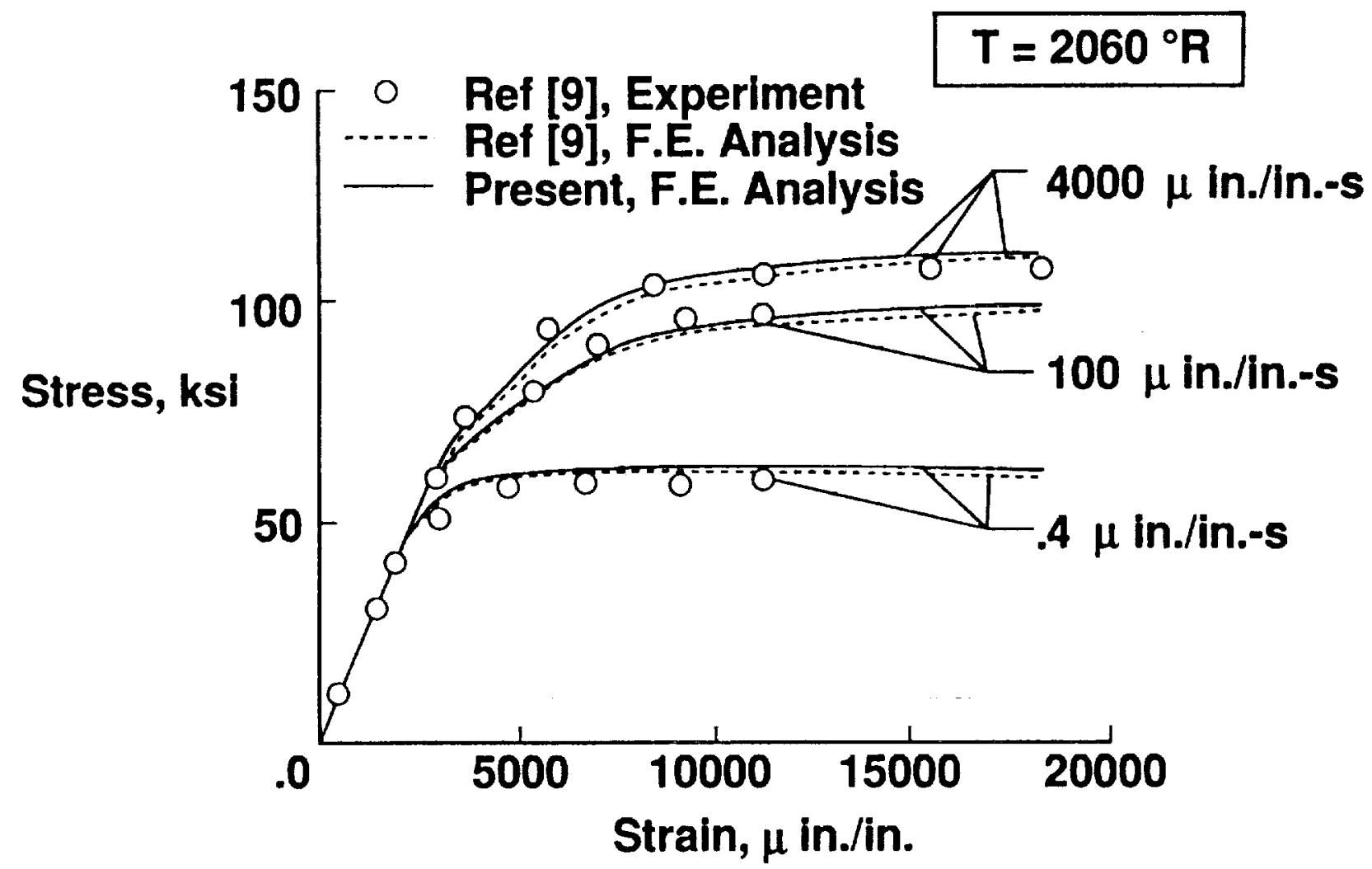

Fig. 2 Effect of varying uniaxial strain rate on the stress-strain curves of a nickel-based superalloy $(\mathrm{B} 1900+\mathrm{H})$ bar at a uniform temperature of $2060^{\circ} \mathrm{R}$. 


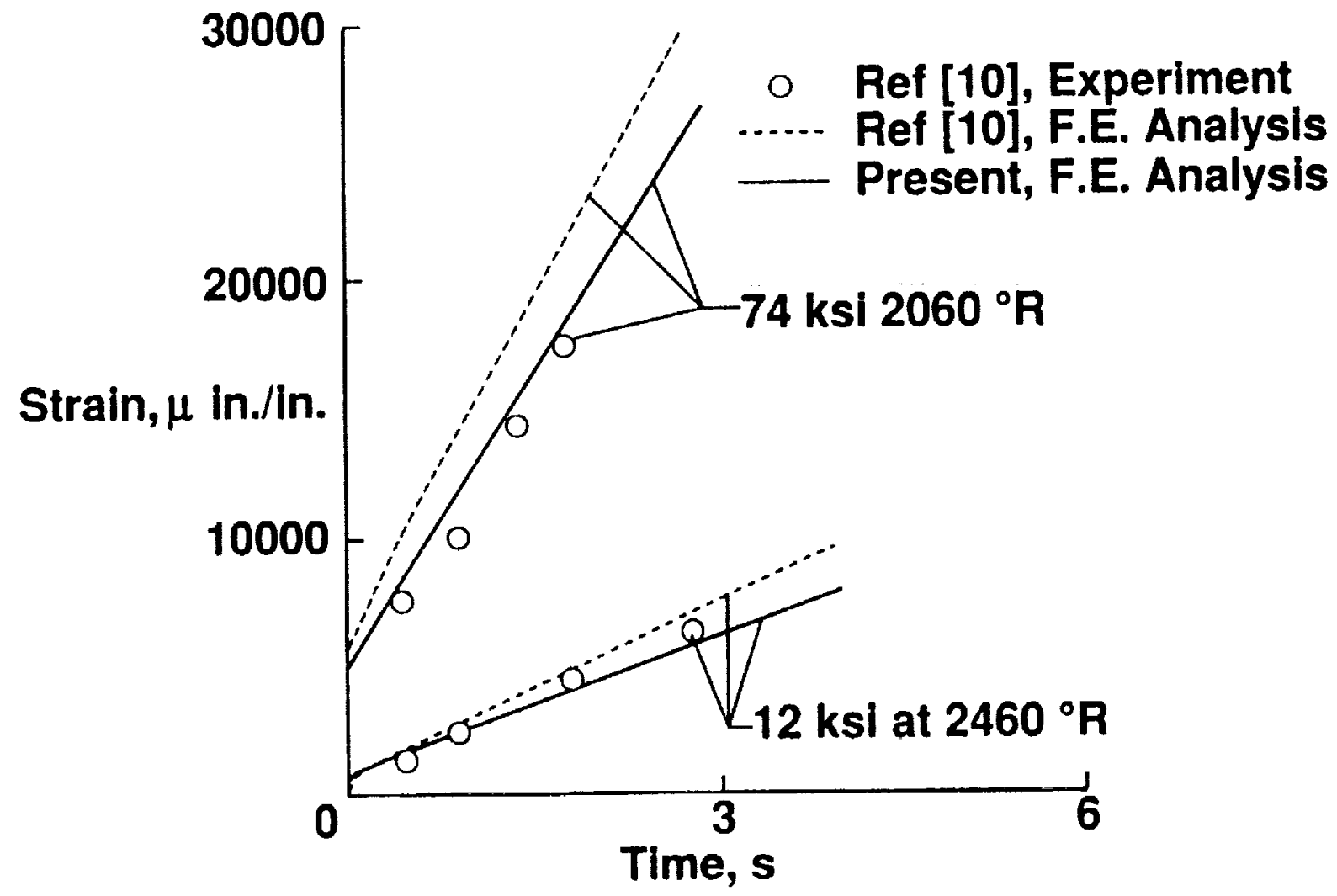

Fig. 3 Time dependent strain in a nickel-based superalloy (B 1900+HI) bar subjected to a constant load at two difrerent temperatures.

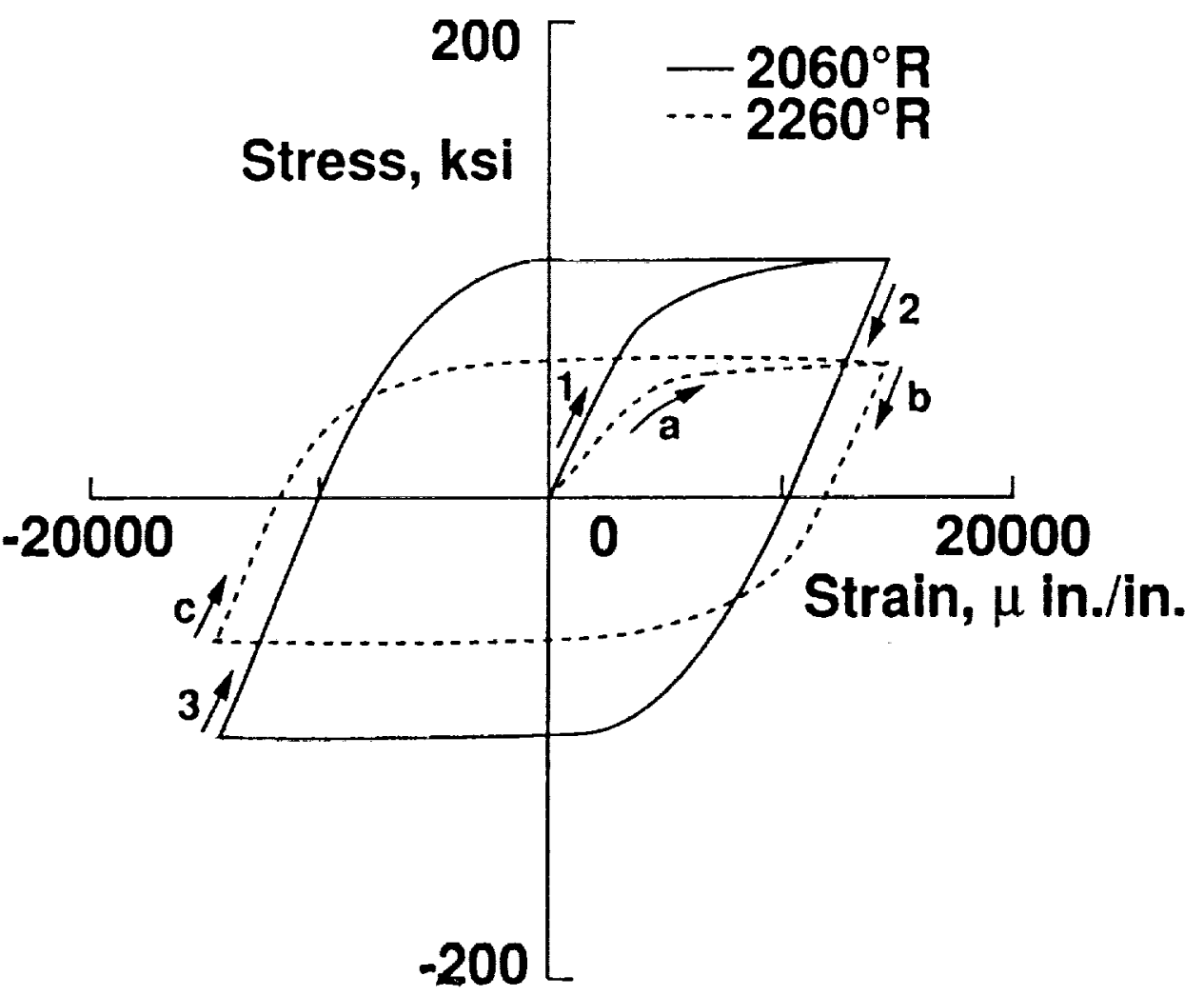

Fig. 4 Predicted stress-strain curves due to uniaxial cyclic loading of a nickel-based superalloy (B1900+Hn) bar at two different temperatures and at a strain rate of $100 \mu$ in.fin.-s. 
The thermo-elastic behavior of a flat plate subjected w local heating was investigated in the early 1950 s [13]. The investigation consisted of theoretical study based on approximate analytical solutions and an experimental study of rectangular aluminum plates. In the experimental study, simple "tcnt like" steady-state temperature distributions were introduced by heating a rectangular plate along a centerline with a heating wire and maintaining constant temperatures along parallel edges by water flow through coolant tubes. Top and bothom surfaces of the plate were insulated to produce uniform one-dimensional, linear temperature variations between the heated centerline and cooled parallel edges. In the experimental study [13], in-plane plate displacements were permilted to occur freely. but out-of-plane displacement were constrained by restraints that forced the plate to remain flat.

In this paper, the thermo-viscoplastic behavior of a rectangular plate is studied assuming the plate is perfectly flat and a state of plane stress occurs. The rectangular plate subjected to line heating along the centerline is shown schematically in Fig. 5. The plate is subjected to a uniform heating rate, $Q, 0.73 \mathrm{Btu} / \mathrm{fl}$-s and the line heating width on the plate is 0.125 in. The top and bottom surfaces of the plate are assumed to be perfectly insulated, and with the assumption of constant therinal properties, the transient temperature distribution can be determined from a one-dimensional analytical solution [14]. For this study, the temperature $T(y, 1)$ was computed Irom,

$$
T(y, l)=\frac{Q(\ell-y)}{2 k}-\frac{4 Q \ell}{k \pi^{2}} \sum_{n=0} \frac{(-1)^{n}}{(2 n+1)^{2}} \operatorname{expl} \frac{-k(2 n+1)^{2} \pi^{2} t}{4 \ell^{2}} \sin \frac{(2 n+1) \pi(\ell-y)}{2 \ell}
$$

where $l=5.0 \mathrm{in}$. is the plate half-width; $k$ is the thermal conductivity; $x$ is the thermal diffusivity; and $t$ is time. The initial temperature of the plate is assumed to be at room temperature $\left(530^{\circ} \mathrm{R}\right)$. Transient temperature distributions, calculated using eq.(11), are shown in Fig. 6 at four instants of time. For times up to $200 \mathrm{~s}$, stecp temperature gradients occur only over the central one-half $(-2.5<y<2.5)$ of the plate. The highly localized temperature change is characteristic of low thermal conductivity nickel-based materials. Because of symmetry, only one-fourth of the plate was modeled in the structural analysis. A reference temperature of $530^{\circ} \mathrm{R}$ was assumed as the stress-free temperature. The finite-element model and the structural boundary conditions are shown in Fig. 7. A stretched mesh was used with small elements along the centerline and near the edge in the region of the steep temperature gradients. The plate structural response was first computed assuming elastic behavior and then viscoplastic behavior.

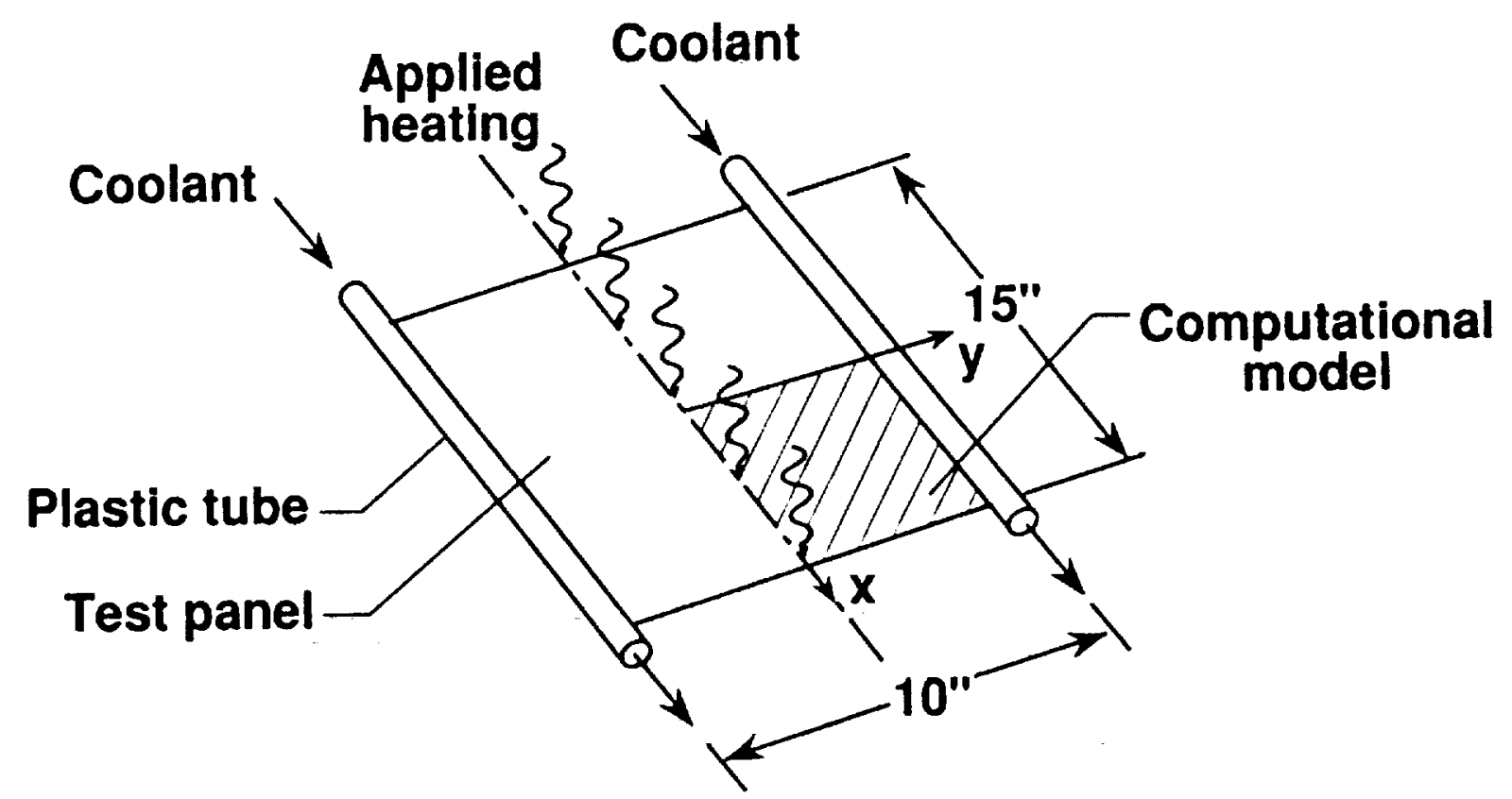

Fig. 5 Schematic diagram of a rectangular plate subjected to line heating along a centerline. 


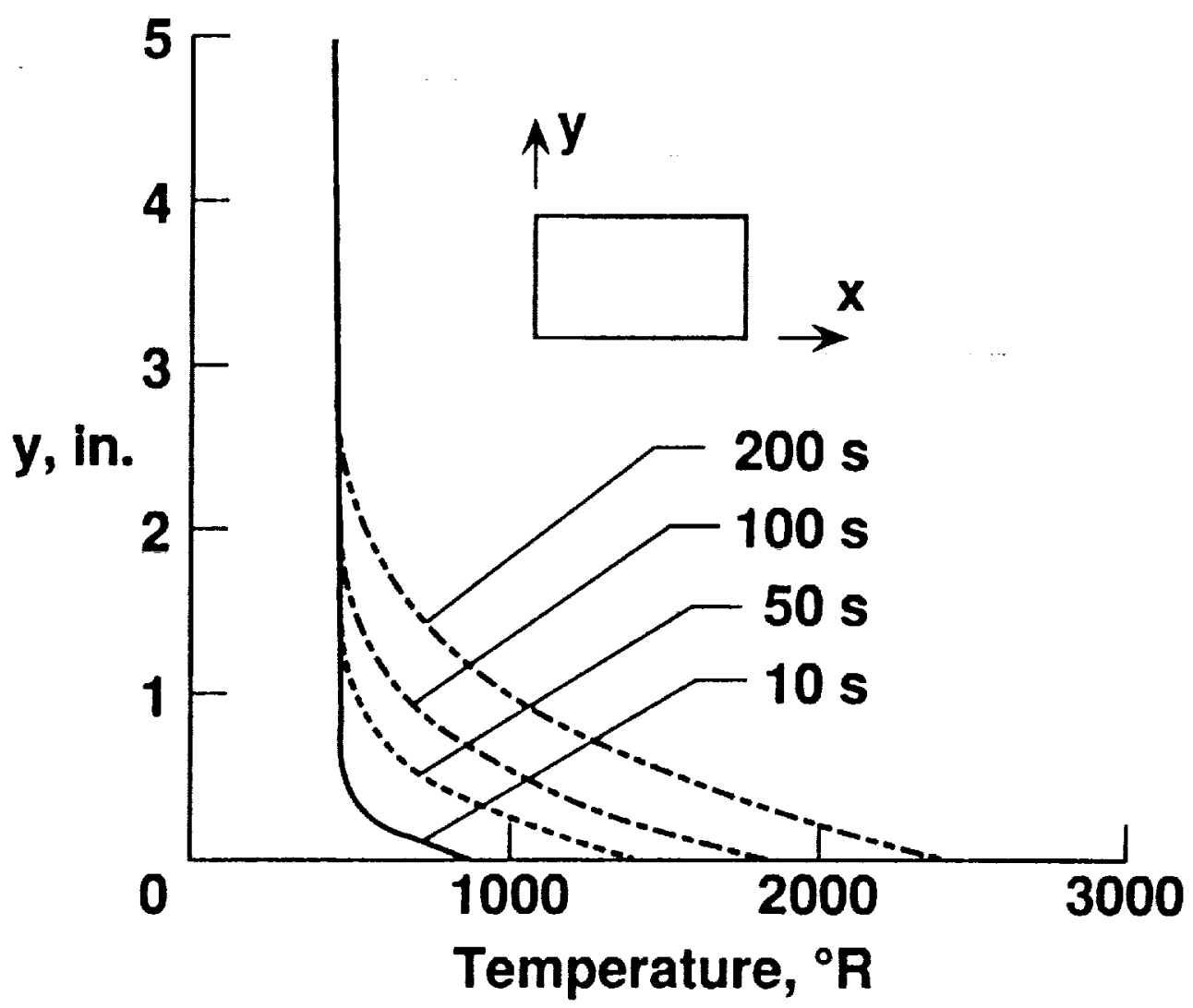

Fig. 6 Plate transient temperature distribution in the direction perpendicular to the centerline.

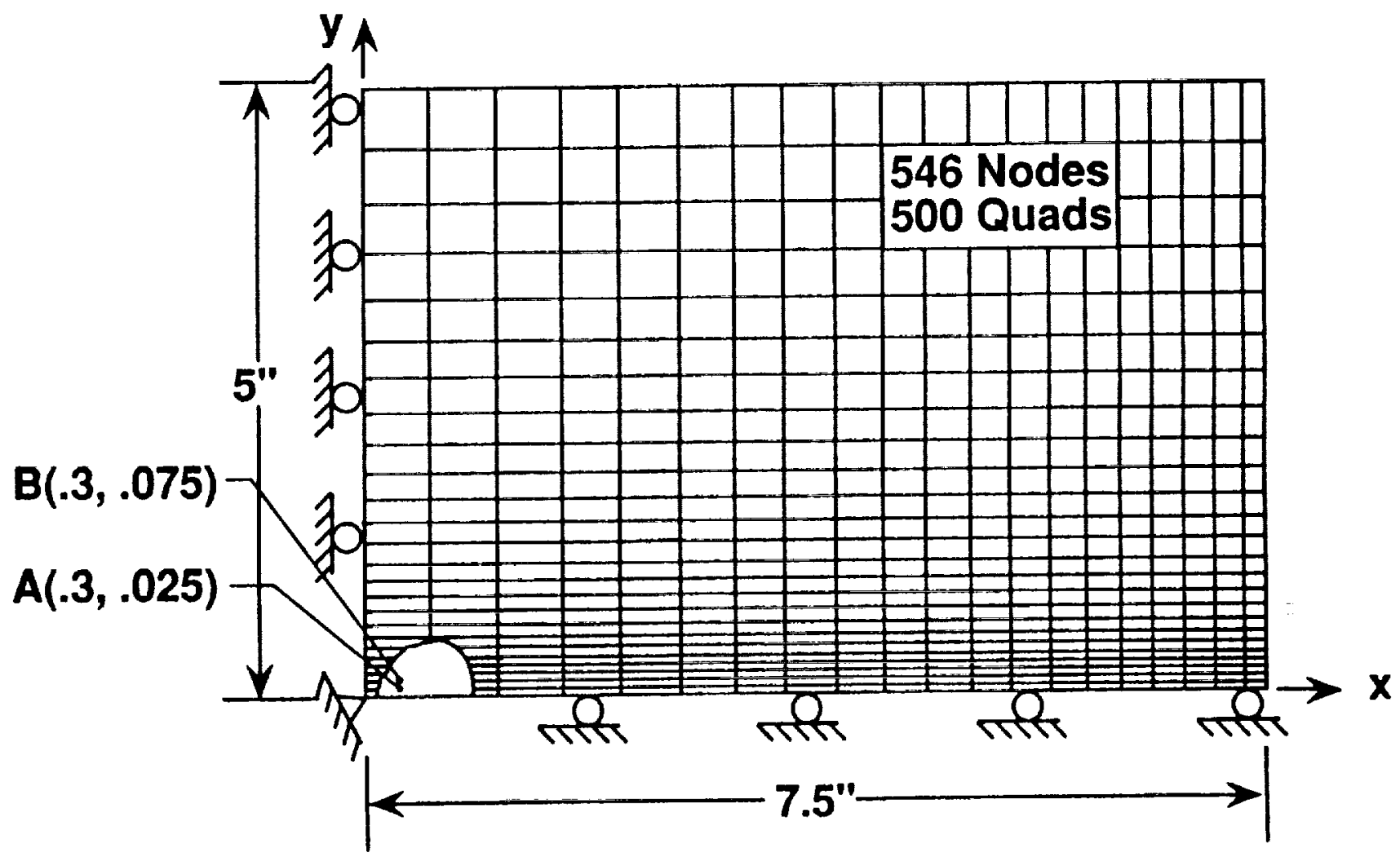

Fig. 7 Finite-clement model and structural boundary conditions of one-quarter of the plate hented along centerline at $\mathrm{y}=0$. 
Temperature histories and comparisons of the elastic and viscoplastic stress ( $\left.\sigma_{x}\right)$ histories at two locations (A and $B$ as marked in Fig. 7) near the center of the plate are shown in Fig. 8. For clastic behavior, the stresses, $\sigma_{x}$, increase monotonically as temperature increases with time (Fig. 8). In contrast to the elastic model, the viscoplastic model predicts yielding early in the response with the stresses remaining nearly constant at $100 \mathrm{ksi}$ for over 100 seconds. The stress at point $A$ decreases afier time $t=120$ seconds duc to the higher temperature at point $A$ and the softening of the material (sec Appendix). A further understanding of the plate response is provided by Figs. 9-10, which show the variation of $\sigma_{x}(x, 0,1)$ and $\sigma_{y}\left(7.5^{\prime \prime}, y, 1\right)$ for the clastic and viscoplastic analysis respectively. As might be expocted the elastic analysis grossly over-estimates the stress levels. The viscoplastic predictions for $\sigma_{x}$ show that the plate yields along the center line at $y=0$ in a region -6 in. $<x<6$ in. very carly in the response at $t$ $=10 \mathrm{~s}$. In contrast, the viscoplastic predictions for $\sigma y$ along the edge at $x=7.5 \mathrm{in}$. (sec Fig. 10) show that the behavior is elastic early in the response, but yielding occurs perpendicular to the plate centerline at about $\mathrm{t}=30 \mathrm{~s}$. Contour plots of $\sigma_{x}$ stresses on the deformed shape of the plate, given in Fig. 11, show regions of maximum stress, $\sigma_{\mathrm{x}}$, for elastic and viscoplastic analysis. The viscoplastic analysis shows that the region near the centerline has reached saturation stress and stresses remain almost constant at about $-110 \mathrm{ksi}$ in this region with increasing temperature.

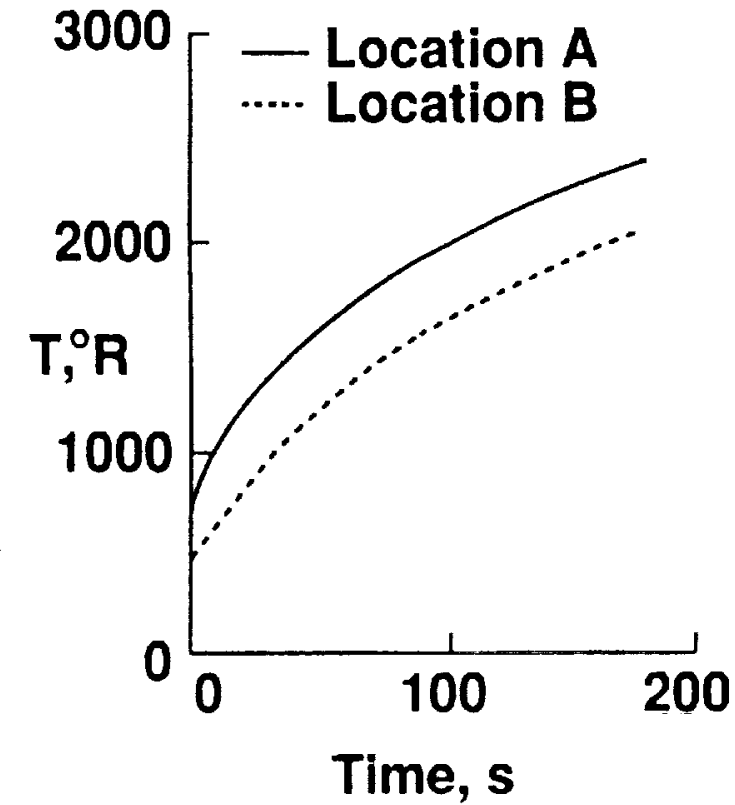

(a) Temperature variation with time

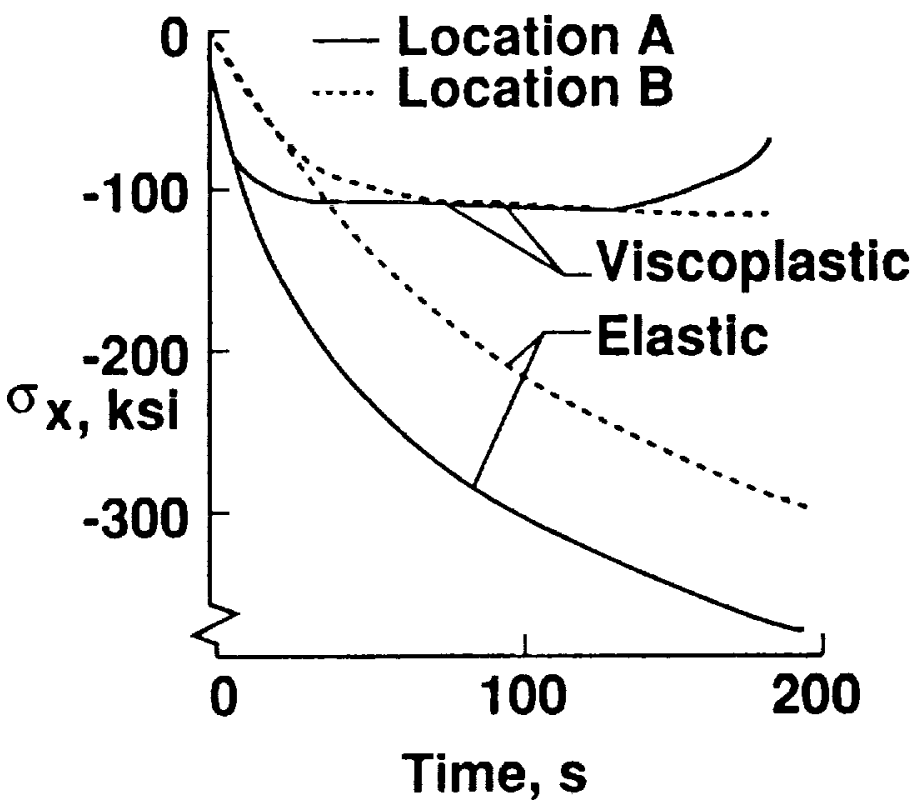

(b) Stress variation with time

Fig. 8 Temperature histories and comparison of elastic versus viscoplastic $\sigma_{2}$ stress histories at two locations in a plate heated along its centerline.

A further measure of the thermally-induced plastic behavior was derived by calculating an effective plastic strain, which is based on the normal and shearing plastic strain components. The effective plastic strain component is decined by [15],

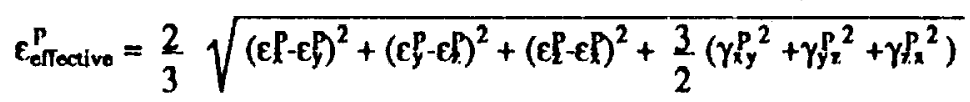

Contours of the effective plastic strain are plotled at four different of times on the deformed plate (sec Fig. 12). 


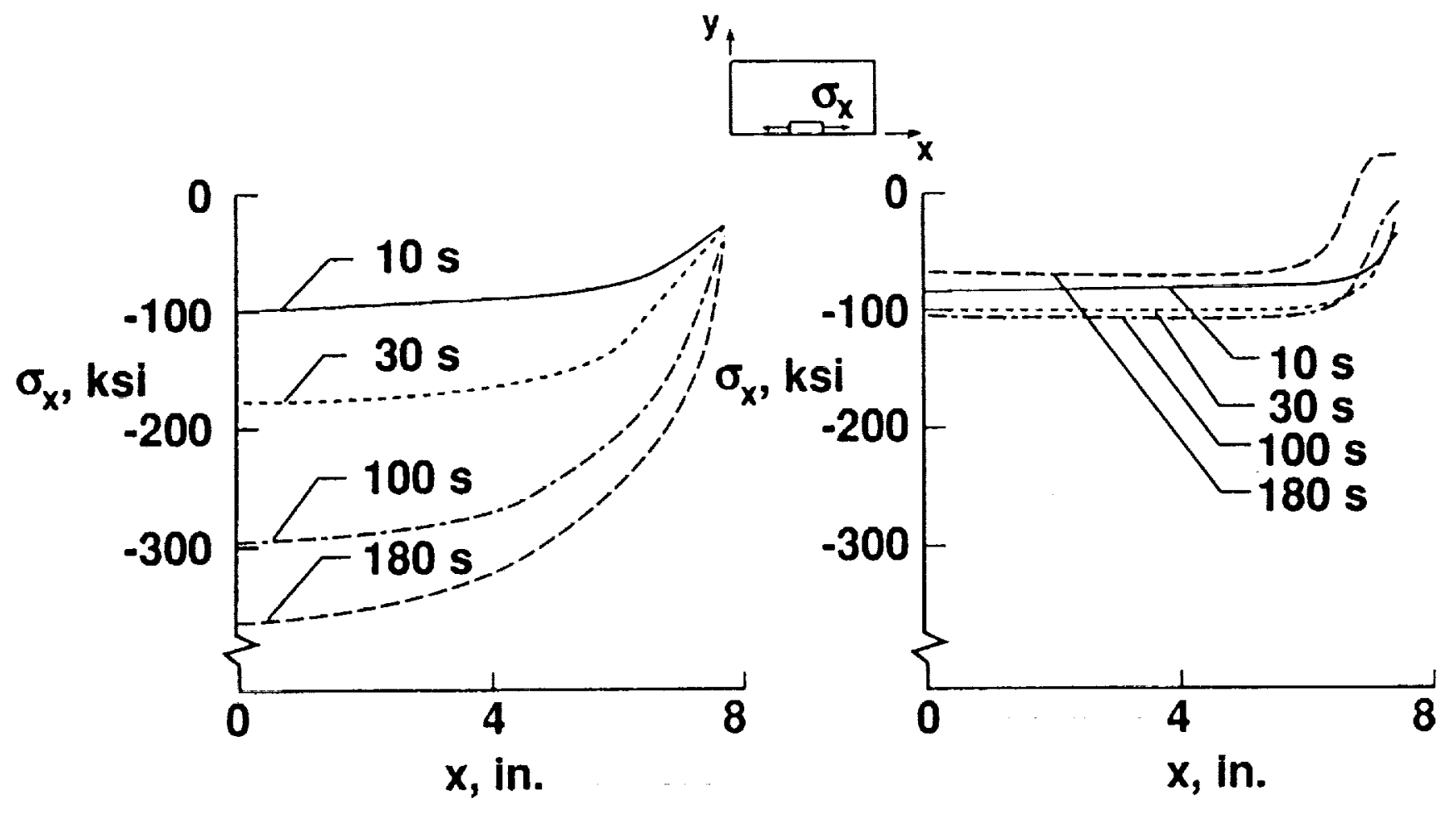

(a) Elastic analysis

(b) Viscoplastic analysis

Fig. 9 Variation of $\sigma_{\mathbf{x}}$ stresses along the centerline of the plate.

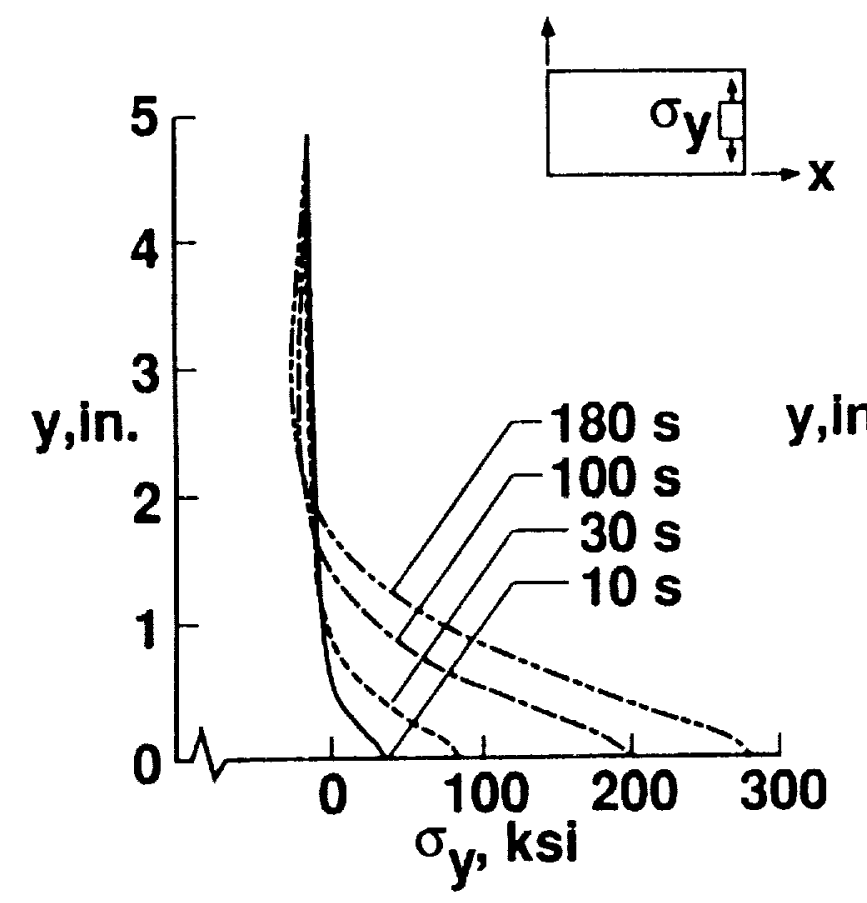

(a) Elastic analysis

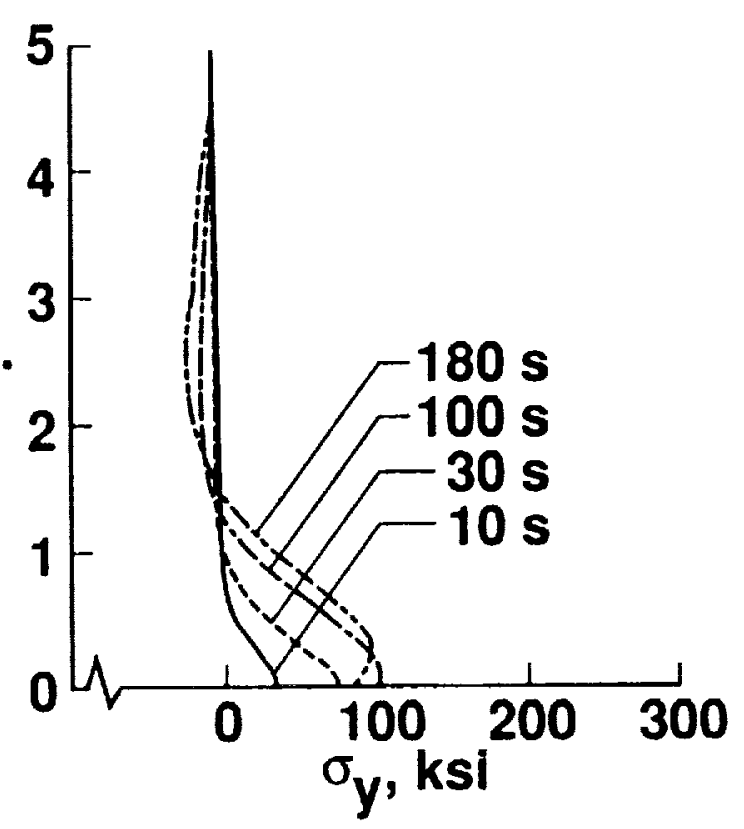

(b) Viscoplastic analysis

Fig. 10 Variation of $\sigma_{y}$ stresses along the free cdge of the plate. 

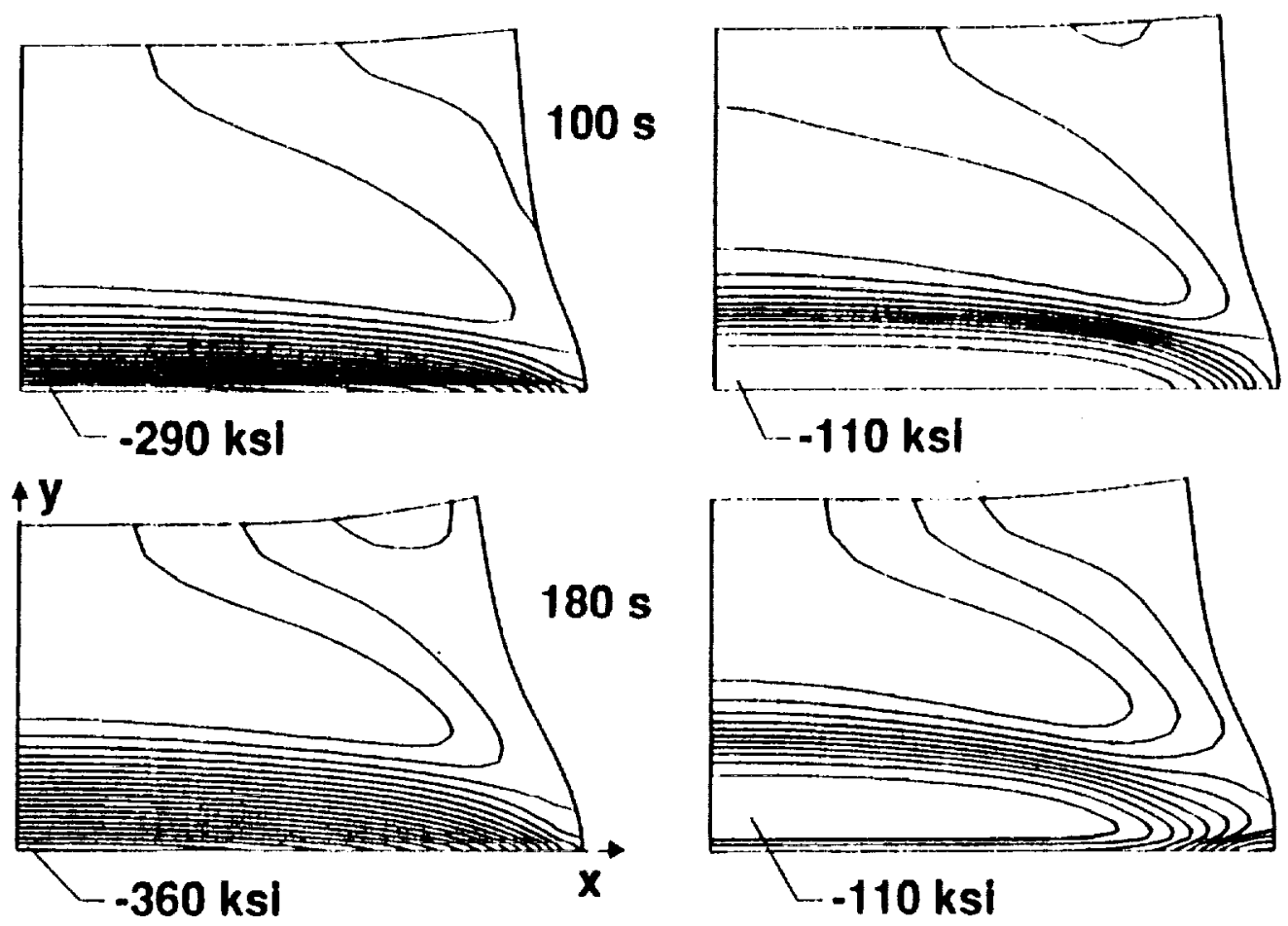

(a) Elastic analysis

(b) Viscoplastic analysis

Fig. 11 Elastic and viscoplastic $\sigma_{\mathrm{n}}$ stress contours on deformed plate (plate heated along centerline, $y=0$ ).
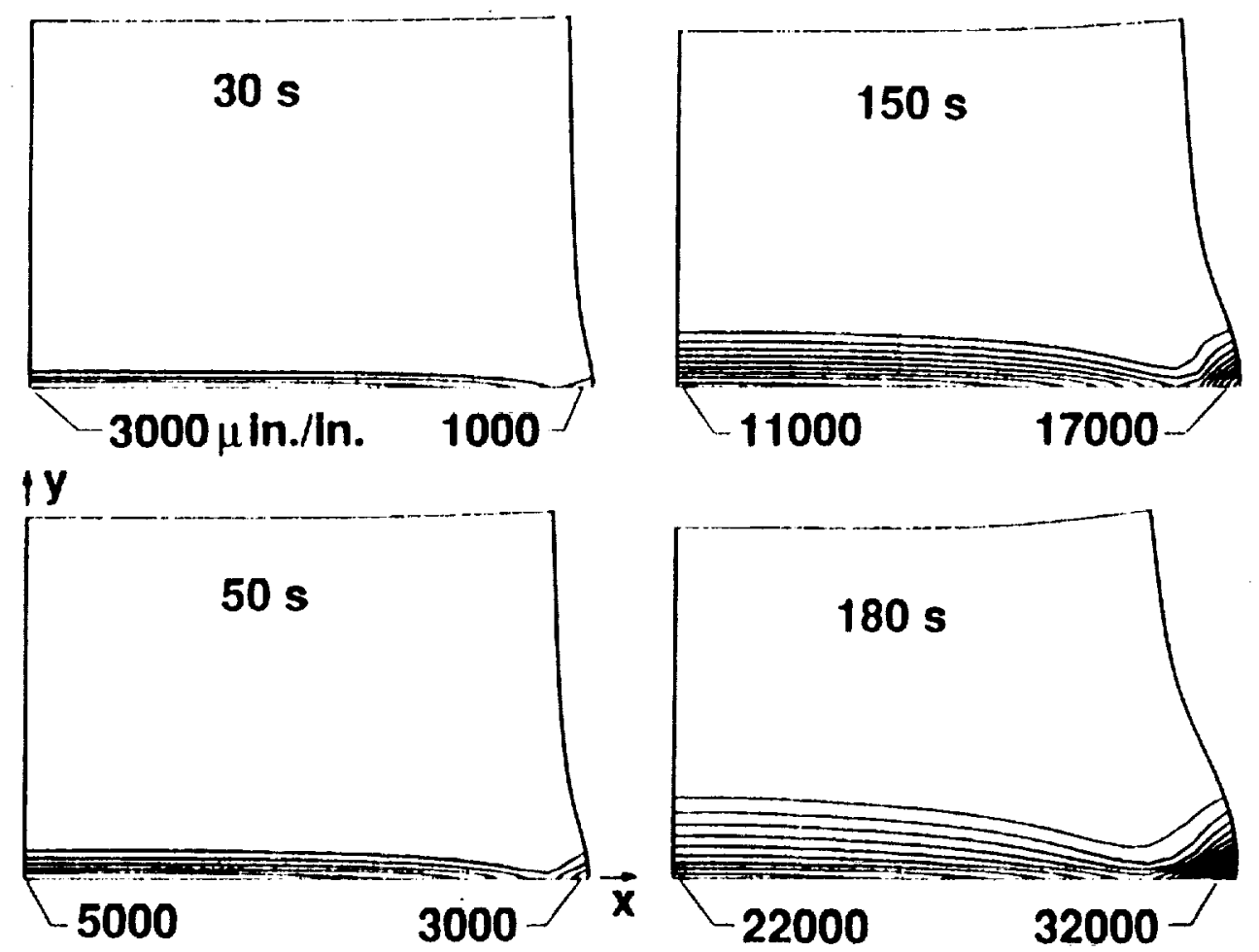

Fig. 12 Effective plastic strain contours, indicating the plastic region and the maximum plastic strain at different times. 
These plots indicate the evolution of the plastically deformed regions near the centerline. The plots show that early in the response for $0 \mathrm{~s}<\mathrm{t}<50 \mathrm{~s}$ the largest inelastic behavior occurs near the plate's center and along the plate's centerline, which are primarily duc $10 \sigma_{\mathrm{x}}$ stress. However, later in the response for $150 \mathrm{~s}<\mathrm{t}<180 \mathrm{~s}$, the largest plastic strain occurs on the plate centerline at the free edges at $x= \pm 7.5 \mathrm{in}$. which is induced by the dominant $\sigma_{y}$ stress at that location. These results indicate that after the plate returns to room temperature permanent contractions can be expected along the plate centerline at $y=0$, and permanent elongations can be expected along the edges $x=$ \pm 7.5 in.

Computational results for this example problem indicate that large, local temperature gradients induce significant plastic behavior over a narrow band along the plate centerline. The viscoplastic analysis of the plate was performed using a time step of $0.1 \mathrm{~s}$. The analysis required two hours of CPU time on CRAY-2 to obtain the plate viscoplastic response. Computation of elastic solutions at the selected times (one second interval) required $\mathbf{8 0 0}$ scconds of CPU time.

\section{Engine Cowl Leading Elge}

Aerodynamically heated leading edges are a critical design problem for scramjet engine struclures of hypersonic vehicles because of the highly localized, intense aerothermal loads induced by shock-shock interactions. The flow interaction at the scramjet engine inlet for the acrospace plane cowl leading edge is schematically shown in Fig. 13. The problem has been the subject of a number of studies [1,2]. A flow-thermal-structural study [1] describes a finite-element approach used in prediction of the acrothermal loads, the struclural temperatures, and the structural response of a convectively-cooled leading edge. In this study, super-thermal conductivity materials were cvaluated, relative to their ability to alleviate elevated leading edge temperatures, temperature gradients, and attendant stress levels. Another study [16] evaluated an adaptive, unstructured finite-element approach for integrated huidthermal-structural analysis by analyzing a convectively-cooled leading edge made of copper. A recent study [17] describes a three-dimensional thermal-structural analysis of a swept cowl leading edge subjected to interference heating. In the latter study [17], the computed peak stresses were beyond the elastic range, and a need for the plastic analysis was indicated.

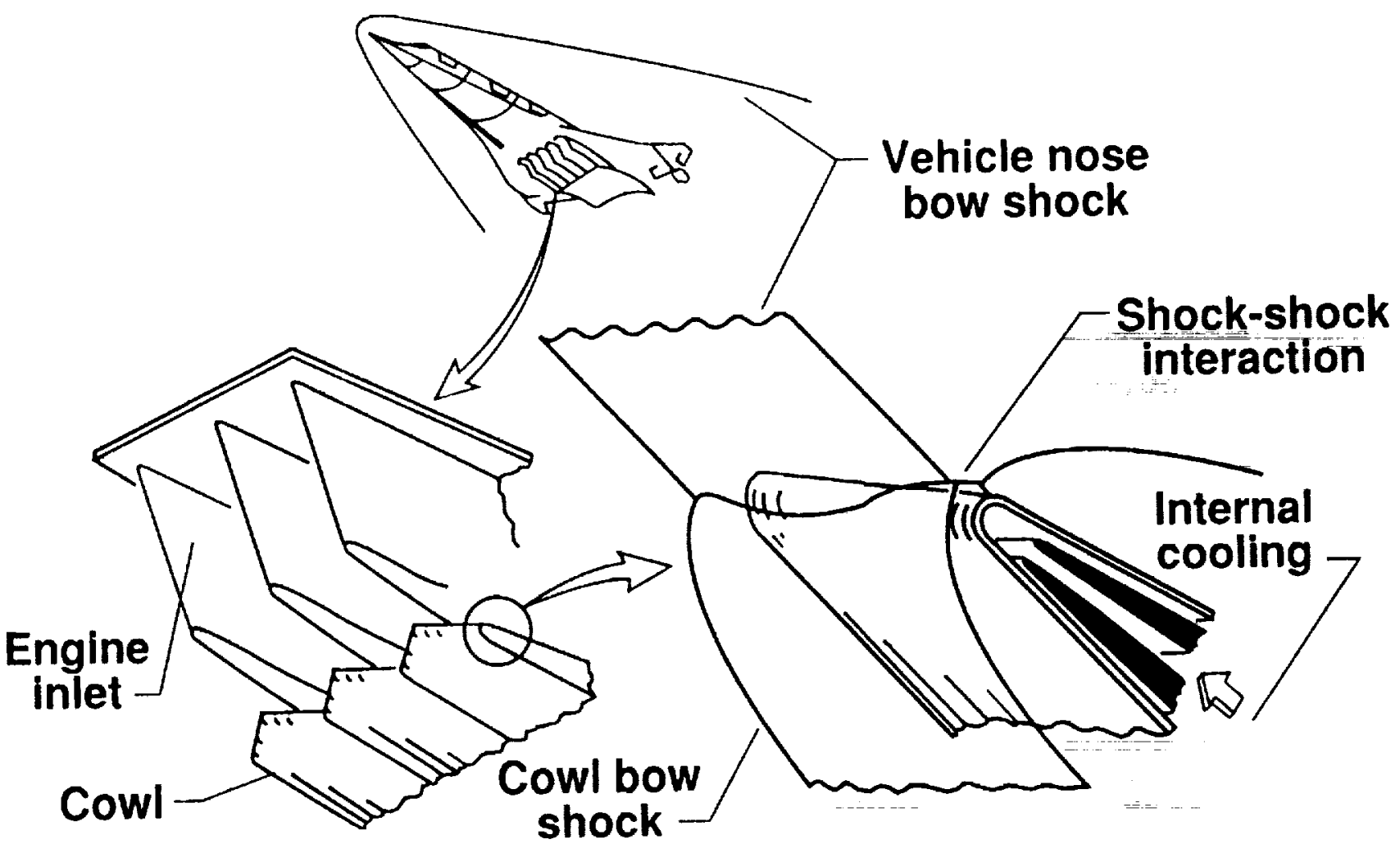

Fig. 13 Schematic diagram of now interaction at scramjet engine inlet for aerospace plane cowl leading edge. 
The purpose of this example problem is to evaluate the significance of viscoplastic behavior on the thermal structural response of a leading edge made from the low thermal conductivity, high ductility, B1900+HI nickel superalloy material. This material was selected because the material constants for viscoplastic model are available for a wide range of temperatures. The leading edge geometry and boundary conditions are shown schematically in Fig. 14. The outer edge is subject to intense, highly localized, transient aerodynamic heating and emits radiant energy to space. The inner surface is convectively cooled by the direct impingement of a hydrogen fow at a constant temperature of $50^{\circ} \mathrm{R}$. The coolant convective coefricient is $7.8 \mathrm{Btu} / \mathrm{ft} \mathbf{2}_{-\mathrm{s}}{ }^{\circ} \mathrm{R}$. The coolant flow occurs at an internal pressure of $1000 \mathrm{psi}$ which is assumed to be uniform over the internal surface. The leading edge has an extemal radius of $0.125 \mathrm{in}$. and a wall thickness of $0.015 \mathrm{in}$. The assumed structural boundary conditions, shown in Fig. 14, prohibit horizontal displacement at the supports, but permit the leading edge to expand or contract in the vertical direction.

The specified aerodynamic heating on the outer surface of the leading edge is shown in Fig. 15. The heat flux shown is a consequence of a shock interaction that occurs as the vehicle accelerates through Mach 16 . The interaction results from the vehicle's nose bow shock sweeping across the leading edge and intersecting the leading edge bow shock (see Fig. 13). The distribution shown in Fig 15a is based on experimental and computational studies described in [1] and the references contained therein. The assumed time history of the aerodynamic heating is shown in Fig. 15b. The leading eige is subjected to the intense heat flux pulses each of $6 \mathrm{~ms}$ duration. The shock on the leading is assumed stationary during this $6 \mathrm{~ms}$ duration, which represents the time required for the shock to sweep across the leading edge. In addition to the aerodynamic heating, an external surface pressure with a peak value of $1000 \mathrm{psi}$ is also imposed. The spatial and temporal distributions of the external surface pressure are the same as the heat flux (see Fig. 15a and 15b).

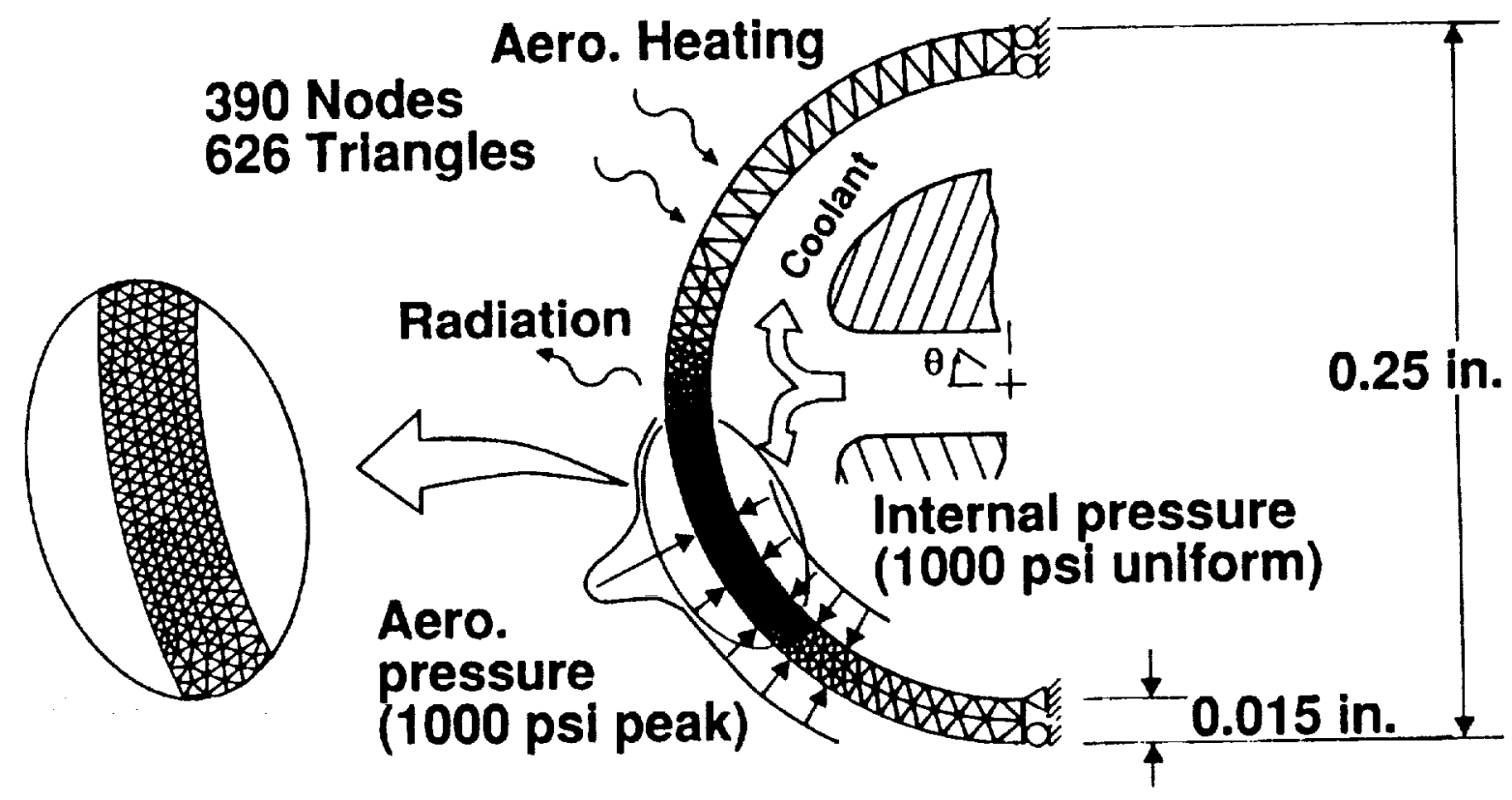

Fig. 14 Finite-element model of the convectively-cooled leading edge structure with applied loads and boundary conditions. 


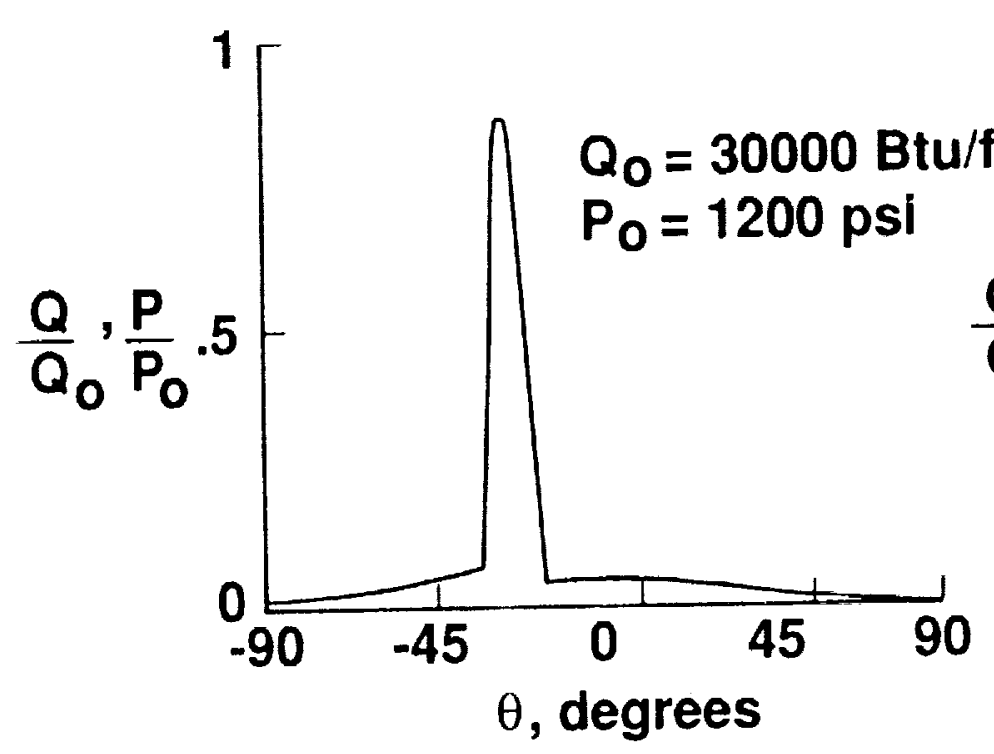

(a) Aerodynamic healing and pressure profile

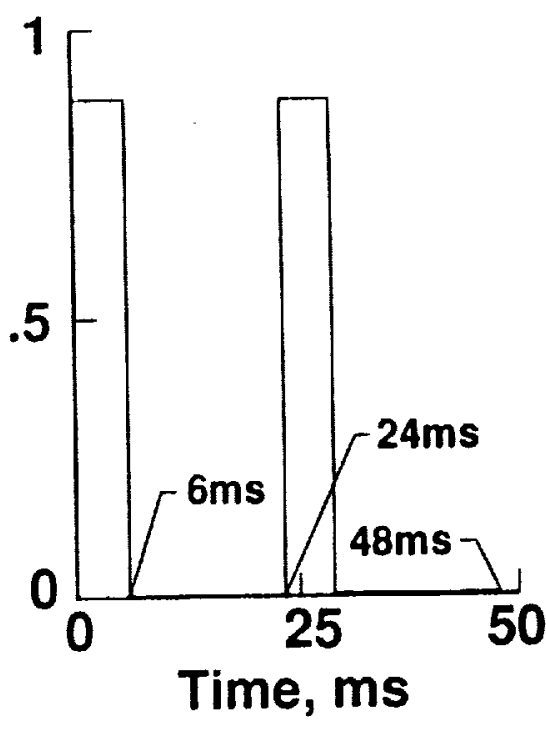

(b) Peak loading histrory

Fig. 15 Acrodynamic heating and external pressure profiles along the outer surface and the peak load history.

The finite-element two-dimensional thermal and structural analyses were performed using the unstructured mesh containing 390 nodes and 626 triangles which is shown in Fig. 14. This mesh was developed in reference [16] using an adaptive procedure that clustered small elements in regions of stecp temperature gradients. Plane strain condition is assumed for the structural analysis. A time step of $0.01 \mathrm{~ms}$ was chosen for the viscoplastic analysis. The computations were performed on CRAY-2 computer and the viscoplastic analysis required 3.0 hours of cpu time. The analysis required $1000 \mathrm{cpu}$ seconds to obtain elastic solutions at desired times.

Temperature histories predicted at two locations on the leading edge are shown in Fig 16. The temperature histories correspond to two points directly under the most intense lweat flux, point A on the outer surface and point B the inner surface (Fig. 16a). The "saw-tooth" response at point A corresponds to the heat pulses shown in Fig. $15 \mathrm{~b}$. The initial heat pulse causes the surface temperature to rise rapidly to a peak of $2550^{\circ} \mathrm{R}$ at $6 \mathrm{~ms}$. After the peak, the temperature decays to about $900^{\circ} \mathrm{R}$ before the second heat pulse increases the temperature at $24 \mathrm{~ms}$. The temperature rises again to a second peak of about $2550^{\circ} \mathrm{R}$ at $30 \mathrm{~ms}$. The tcmperature response at point $B$ on the inner surface shows a relatively small increase of about $200^{\circ} \mathrm{R}$ corresponding to the external heating. This small wmperature change shows the predominant role of the internal convective cooling. Temperature contours at $6 \mathrm{~ms}$ are shown in Fig. 16b. These contours show the highly localizal heat-affected region, and the very stecp temperature drop from the ouler to the inner surface.

Using these prescribed temperatures, the structural response was computed quasi-statically assuming: (1) elastic material behavior, and (2) inclastic material behavior according to the Bodner-Partom model.

Circumferential stress historics at points $A$ and $B$, us predicud by the clastic and viscoplastic analyses, are shown in Fig. 17. Al time $\iota=0$ when the external pressure, internal pressure, and external heating are instantaneously applied, local bending introduces compressive initial stress on the outer surface and tensile stress on the inner surface. Thereafter, the stress histories reflect a complex interplay belween thermal stress and temperaturedependent inclastic malerial behavior. During the first heat pulse, lemperalure on the outer surface rises very rapidly introducing high compression stresses at point $A$. The viscoplastic analysis predicts yiclding within $1 \mathrm{~ms}$. Point B at this time experiences small compressive stresses. Temperature on the outer surface rises to the peak value of about $2550^{\circ} \mathrm{R}$ in only $6 \mathrm{~ms}$ during the first heat pulse. On the outer surface, the material softens with a stecp reduction in the elastic modulus. At the same time, the stecp temperature gradient introduces a significant thermal bending moment. After the heat pulse ends at $6 \mathrm{~ms}$, the bending moment persists, causing increasing tensile 
stresses at point B until a peak is reached at about $8 \mathrm{~ms}$. The viscoplastic analysis predictions suggest slight tensile yiclding for point B at this time. From $6 \mathrm{~ms}$ until the second heat pulse occurs at $24 \mathrm{~ms}$, the stress at point A remains roughly constant, but the stress at point B decreases as the wall temperature gradient diminishes. At $24 \mathrm{~ms}$, the second heat pulse begins, temperature increases rapidly and the stress historics tend to repeat their first cycles. The axial stresses (perpendicular to analysis plane) for the elastic analysis are much higher than the in-plane stresses (circumferential and radial stresses) due to plane-strain constraint, but the viscoplastic axial stresses are of comparable value to the viscoplastic in-plane stresses.

During the two heat pulses, the predicted elastic and viscoplastic stresses follow cach other closely. The most significant difference in stresses occur at $25 \mathrm{~ms}$. Comparison of stress contours for the elastic and viscoplastic analyses at $\mathrm{t}=\mathbf{2 5} \mathrm{ms}$ is shown in Fig. 18. The stress contours show steep gradients from the outer to inner surface, and stresses are confined locally to the heat affected region as might be expected. Although the viscoplastic and elastic stresses are at similar levels over much of the response, consideration of the stress levels alone does not fully explain the behavior. At saturation stress level, significant plastic strain occurs. This is particularly true at point A where the highest temperature is experienced. At very high temperalures, the saturation stress level is reduced (see Fig. 1) and considerable plastic strain may be caused by relatively low stresses.

Contours of effective plastic strains at four times in the response are presented in Fig. 19 (for reference, yielding occurs at a strain of about $2000 \mu \mathrm{in}$./in. at room temperature). The figure shows that point $A$ sustains a plastic strain of $12000 \mu \mathrm{in}$./in. over the period of $24 \mathrm{~ms}$ due to the first heat pulse. The second heat pulse causes less plastic strain due to built-in residual stresses, but a total of $17000 \mu \mathrm{in}$./in. accumulates after $48 \mathrm{~ms}$. The contours suggest that the largest plastic strains occur ncar the outer surface although small plastic strains are experienced through the wall thickness. These plastic strains will result in permanent deformations and residual stresses after the leading edge temperatures have returned to steady-state conditions.

The elastic and viscoplastic analyses of a two-dimensional model of the leading edge provide valuable insight into the local thermal-structural behavior at elevated temperalures. For the nickel superalloy material studied, significant permanent plastic strain results. To understand the three-dimensional viscoplastic behavior of the leading edge, further study is required.

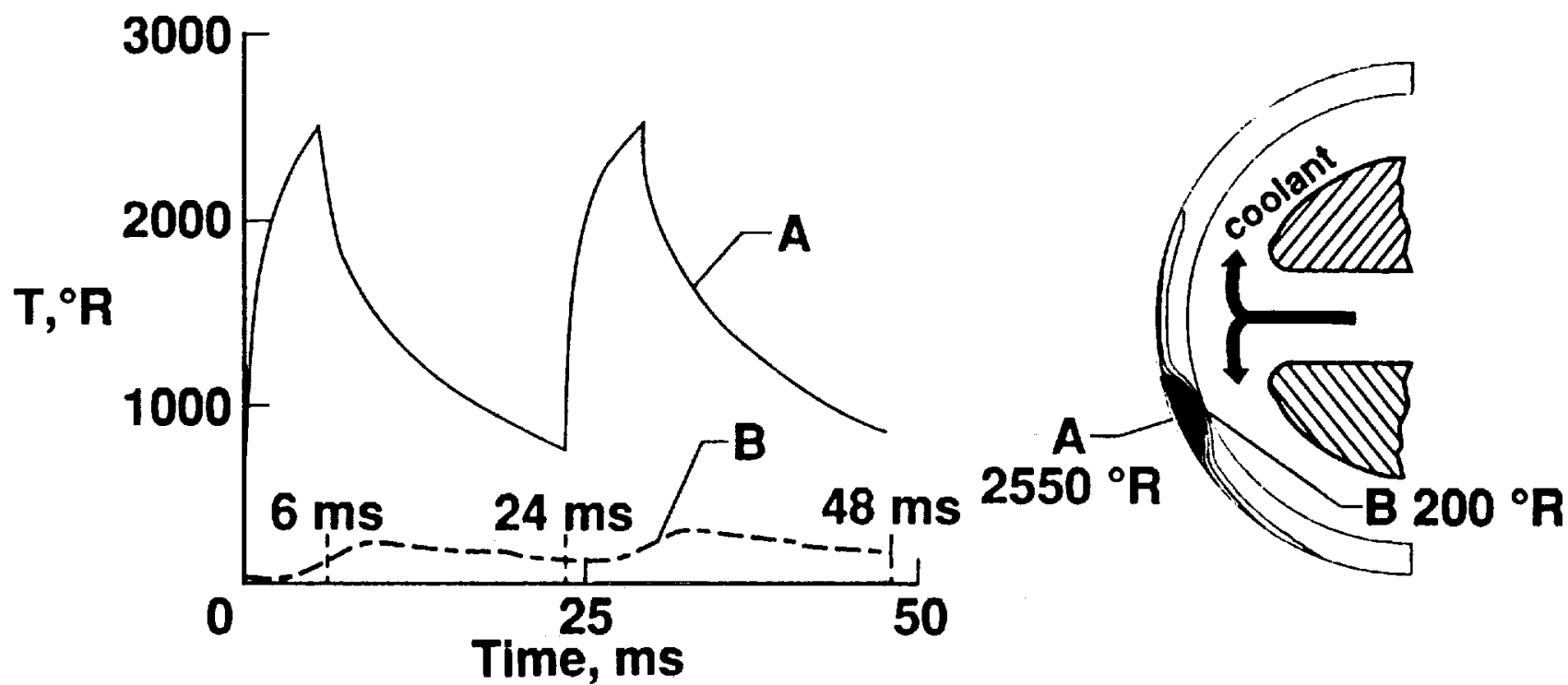

(a) Temperature variation with time

(b) Temperature contours at $6 \mathrm{~ms}$

Fig. 16 Temperature history of two locations and the leading edge temperature contours at $6 \mathrm{~ms}$. 


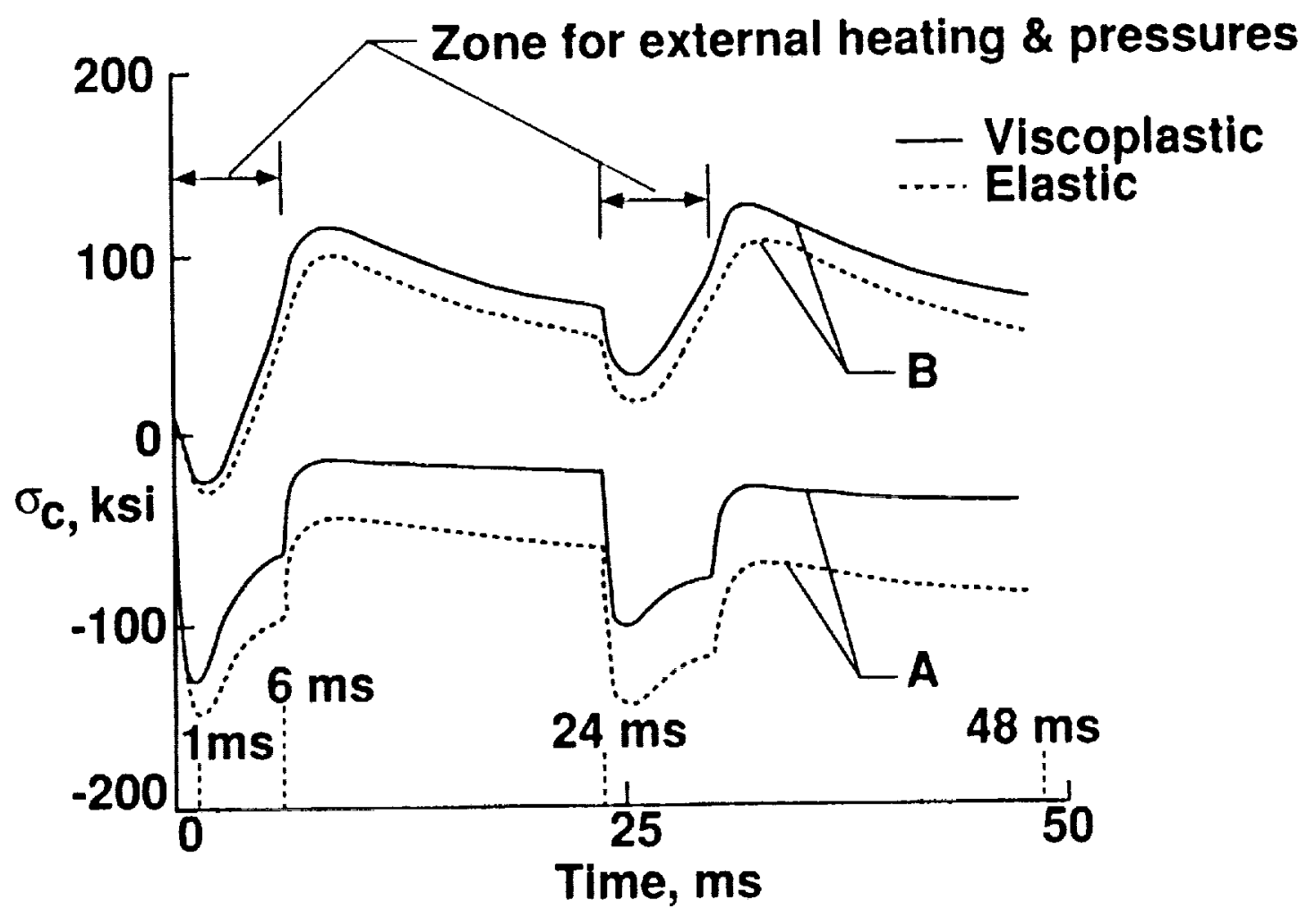

Fig. 17 Comparison of circumferential stresses at two locations for elastic and viscoplastic analysis.

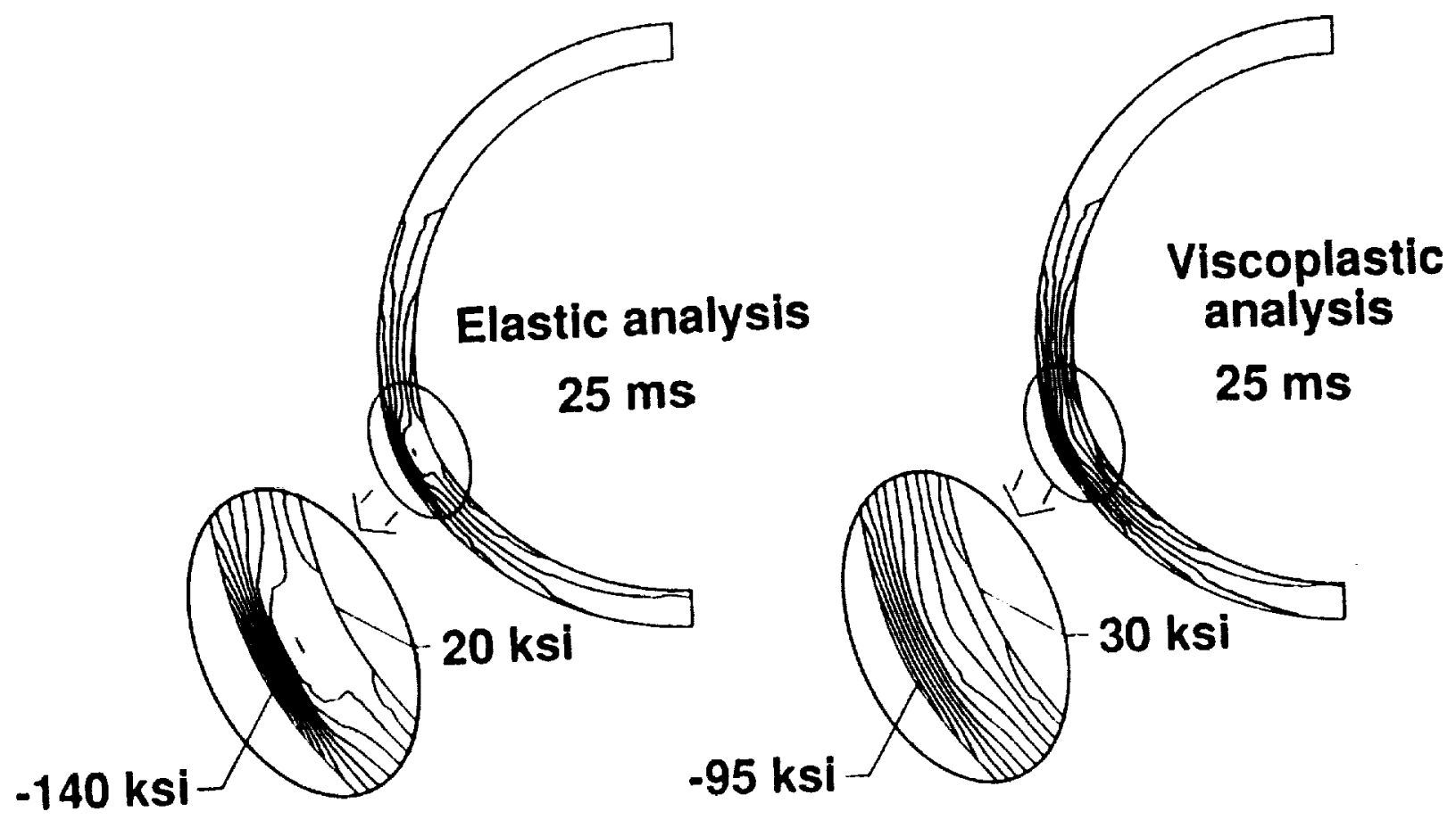

Fig. 18 Circumferential stress contours for elastic and viscoplastic analysis. 


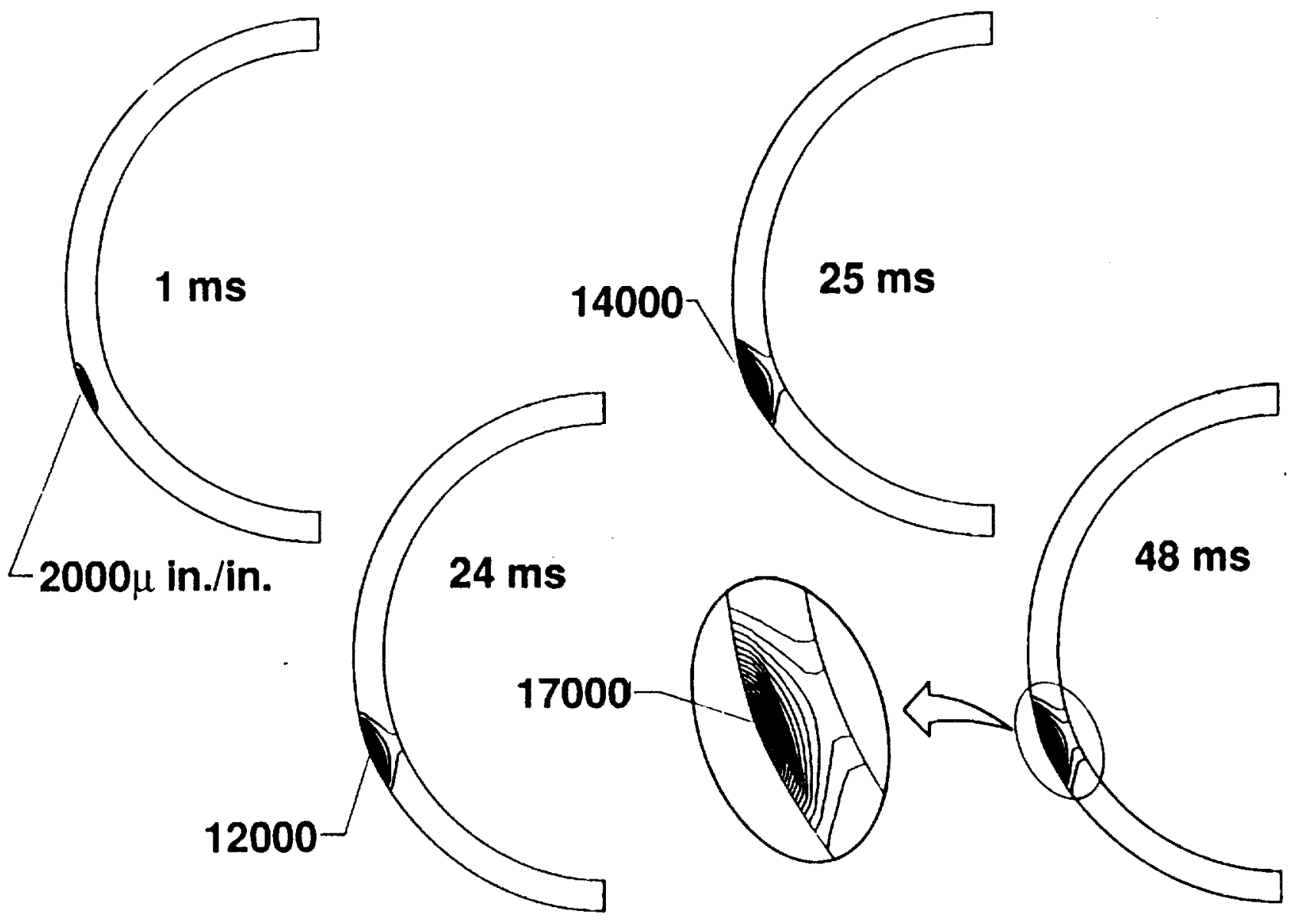

Fig. 19 Effective plastic strain contours indicating the propagation of plastic region and maximum plastic strain.

\section{CONCLUDING REMARKS}

A thermo-viscoplastic computational method for structures subjected to severe local heating is used to investigate the transient thermal-structural behavior of scveral problems of current interest. The method employs the Bodner-Partom unified viscoplastic constitutive model implemented in a finite-element approach for quasi-static thermal-structural response.

The analysis method was verified by comparing with previous uniaxial experimental and numerical results using B 1900+Hf nickel superalloy material. The two application problems considered were: (1) a flat plate in plane stress condition subjected to line heating along the plate centerline, and (2) a convectively-cooled leading edge in planc-strain condition subjected to localized heating representing a shock-shock interaction. Elastic and viscoplastic analyses were compared for each of the problems. The elastic analysis tended to over-estimate stresses and, of course, did not predict plastic deformations. The viscoplastic analysis predicted local yielding and provided insight into the history of multi-dimensional inelastic behavior induced by transient heating. The viscoplastic analyses are relatively expensive in comparison to clastic analysis and lack experimental validation. Yet this study shows that such analyses can have a valuable role in understanding complex transicnt struclural behavior at elevated icmperalures. 


\section{REFERENCES}

1. P. Dechaumphai, E. A. Thornton and A. R. Wicting. "Flow Thermal-Structural Study of Aerodynamically Heated Leading Edge," Joumal ol Spacecraft and Rockets, Yol. 26, No. 4, July 1989, pp. 201-209.

2. M. W. Melis and H. J. Gladden, "Thermostructural Analysis with Experimental Verification in a High Heat Flux Facility of a Simulated Cowl Lip," AIAA Paper No. 88-2222. April 1988.

3. S. R. Bodner and Y. Partom, "Constitutive Equations for Elastic-Viscoplastic Strain-Hardening Materials," Journal of Applied Mechanics, Vol. 42, 1975, pp. 385-389.

4. A. K. Miller (editor), Unified Constitutive Equations for Creep and Plasticily, Elscvier Applied Science Publishers, 1987.

5. E. A. Thornton, J. T. Oden, W. W. Tworzydlo and S. K. Youn, "Thermo-Viscoplastic Analysis of Hypersonic Structures Subjected to Severe Aerodynamic Heating," AIAA Paper No. 89-1226, April 1989.

6. H. J. Gladden, M. E. Melis and T. T. Mockler, "Thermal/Structural Analyses of Several Hydrogen-Cooled Leading-Edge Concepts for Hypersonic Flight Vehicles," AIAA Paper No. 90-0053, January 1990.

7. V. Moreno and E. H. Jordan, "Prediction of Material Thermo-Mechanical Response with a Unified Viscoplastic Constitutive Model," AlAA Paper No. 85-0622, April 1985.

8. S. R. Bodner, "Revicw of a Unified Elastic-Viscoplastic Theory," Unified Constitutive Equations for Creep and Plasticity, A. K. Miller, Editor, Elsevier Applied Science Publishers, 1987.

9. U. S. Lindholm, K. S. Chan, S. R. Bodner, R. M. Weber, K. P. Walker and B. N. Cassenti, "Constitutive Modeling for Isotropic Matcrials (HOST)," NASA CR-174980, July 1985.

10. K. S. Chan, U. S. Lindholm, S. R. Bodner, J. T. Hill, R. M. Weber, T. G. Meyer, "Constitutive Modeling for Isotropic Materials (HOST)," NASA CR-179522, July 1986.

11. A. K. Pandey, P. Dechaumphai and A. R. Wieting, "Thermal-Structural Finite Element Analysis Using Linear Flux Formulation," AIAA Paper No. 89-1224, April 1989.

12. K. H. Huebner and E. A. Thomton, The Finite Element Method for Engincers, Second Edition, John Wiley and Sons, 1982.

13. R. R. Heldenfels and W. M. Roberts, "Experimental and Theoretical Detcrmination of Thermal Stress in a Plate," NACA TN-2769, 1952.

14. H. S. Carslaw and J. C. Jaeger, Conduction of Heat in Solids, Oxford University Press, 1980. p. 113.

15. J. O. Smith and O. M. Sidebottom, Inclastic Behavior of Load Carrying Members, John Wiley and Sons, 1965, p. 86.

16. P. Dechaumphai, "Evaluation of an Adaptive Unstructured Remeshing Technique forlntegrated FluidThermal-Structural Analysis," AIAA Paper No. 90-0556, January 1990.

17. S. P. Polesky, P. Dechaumphai, C. E. Glass and A. K. Pandey, "Three-dimensional Thermal-Structural Analysis of a Swept Cowl Leading Edge Subjected to Skewed Shock-Shock Interference Heating," AIAA Paper No. 90-1710, June 1990.

\section{APPENDIX}

Material propertics for nickel-bascd superalloy (B1900+HI)

\section{Thermal Constants}

Density $(\rho)=0.283 \mathrm{lbm} / \mathrm{in}^{3}$

Thermal conductivity (k) and Specific Heat (c)

$\begin{array}{ccc}\text { Temperature }\left({ }^{\circ} \mathrm{R}\right) & \mathrm{k}\left(\mathrm{Btu} / \mathrm{in}-\mathrm{s}-^{\circ} \mathrm{R}\right) & \mathrm{c}\left(\mathrm{Btu} / \mathrm{bm} \cdot{ }^{\circ} \mathrm{R}\right) \\ 0 & 1.23 \times 10^{-4} & 0.12 \\ 500 & 1.80 \times 10^{-4} & 0.135 \\ 1500 & 3.25 \times 10^{-4} & 0.177 \\ 3000 & 6.00 \times 10^{-4} & 0.26\end{array}$


Struclural Constants

1. Elastic Constants

Temperature ( $\left.{ }^{\circ} \mathrm{R}\right)$

492.0

762.0

1032.0

1302.0

1572.0

1842.0

2112.0

2382.0

2652.0

2. Thermal Expansion Coefficient ( $\alpha$ )

Temperature $\left({ }^{\circ} \mathrm{R}\right)$

492.0

852.0

1212.0

1572.0

$E(p s i \times 106)$

$G(p s i \times 106)$

28.88

12.54

28.91

12.22

28.31

11.94

27.09

11.62

25.30

11.14

22.97

10.40

20.13

9.31

16.82

7.76

13.07

5.65

$$
\begin{aligned}
& \alpha\left(\mathrm{in} / \mathrm{in}-{ }^{\circ} \mathrm{R}\right) \\
& 0.638 \times 10^{-5} \\
& 0.744 \times 10^{-5} \\
& 0.755 \times 10^{-5} \\
& 0.783 \times 10^{-5} \\
& 0.855 \times 10^{-5} \\
& 0.888 \times 10^{-5} \\
& 0.922 \times 10^{-5}
\end{aligned}
$$

2292.0

3. Viscoplastic constants

2652.0

Temperalure-independent constants

$$
\begin{array}{rlrl}
\mathrm{m}_{1} & =1.8616 \times 10^{-3} \mathrm{psi}^{-1} ; & \mathrm{m}_{2}=1.0480 \times 10^{-2} \mathrm{psi}^{-1} \\
\mathrm{Z}_{1}=43.51 \times 10^{4} \mathrm{psi} ; & \mathrm{Z}_{2}=16.67 \times 10^{4} \mathrm{psi} \\
\mathrm{r}_{1}=\mathrm{r}_{2}=2 ; & \mathrm{D}_{0}=10000 \mathrm{\textrm {s } ^ { - 1 }}
\end{array}
$$

Temperature-dependent constants

Temperature $\left({ }^{\circ} \mathrm{R}\right)$

n

$\mathbf{Z}_{0}=\mathbf{Z}_{2}$ (ksi)

$A_{1}=A_{2}\left(s^{-1}\right)$
1860

1.055

391.6

0.0
2060)

1.03

348.0

0.0055
$22(0)$

0.85

275.5

0.02
2460

0.70

174.0

0.25 


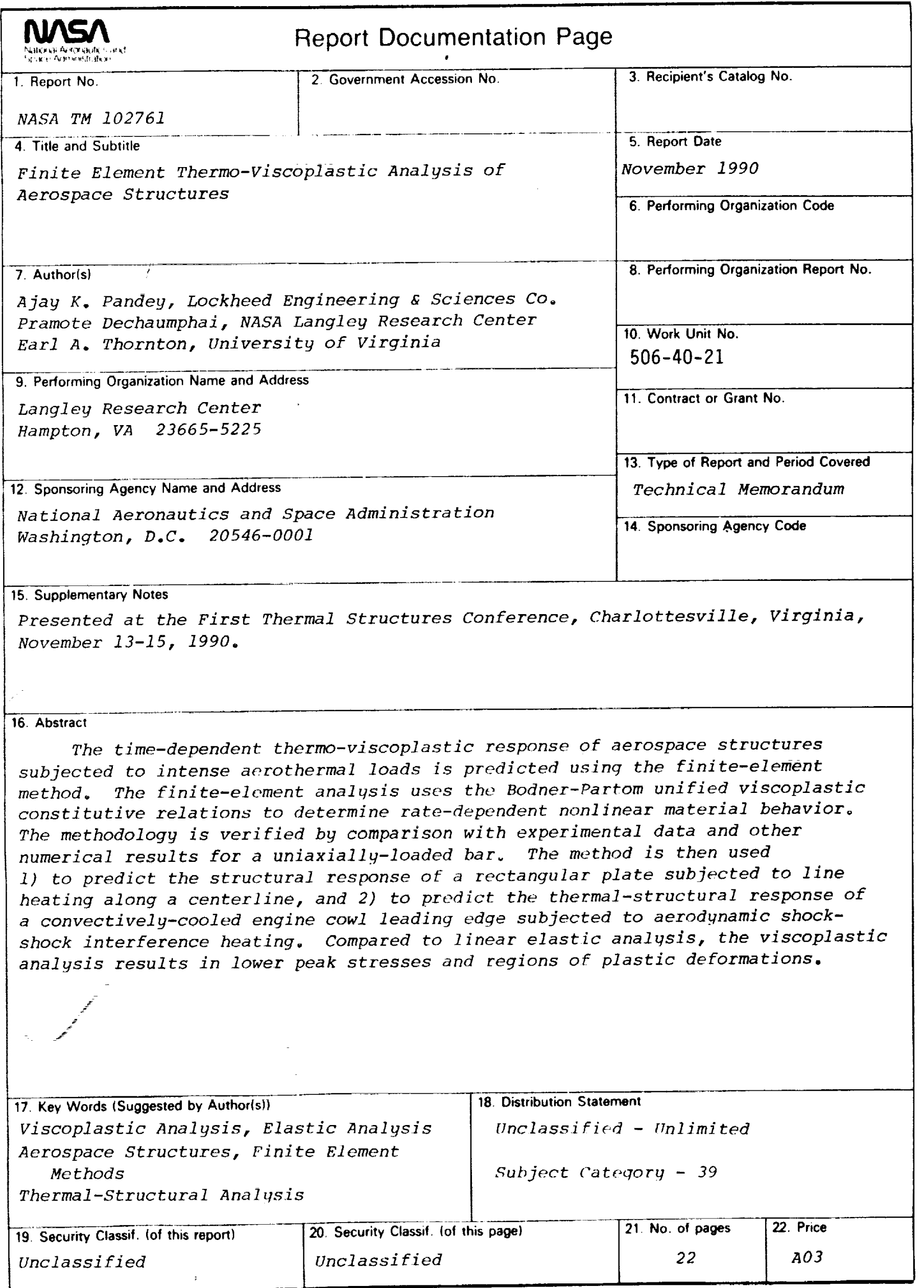

